\title{
Training transitions: From research dependence to
}

\section{independence}

\author{
Harinder Singh ${ }^{1}$, Adriana Bankston ${ }^{1}$, Gary McDowell ${ }^{1,2,{ }^{*}}$ \\ ${ }^{1}$ Future of Research, Pittsfield, MA, USA \\ ${ }^{2}$ Current affiliation: Lightoller LLC, Chicago, IL, USA \\ "Correspondence to: \\ Gary McDowell at info@lightoller.org
}

Future of Research at info@futureofresearch.org 


\begin{abstract}
Academic research is managed through principal investigators overseeing independent research programs. The idealized training to become a principal investigator consists of studying for a PhD, where research skills are developed, possibly followed by postdoctoral research training under the mentorship of another principal investigator. The researcher can then take those skills and apply them to the management of a multi-person project. However, in the present scientific research climate, early career researchers (ECRs, broadly graduate students and postdocs) face obstacles to establishing their own independent research programs. To gather data on the experiences of ECRs in academia, we organized a series of workshops discussing the barriers they experience to research independence, and solicited their proposals of solutions to overcome them. Barriers identified included: a lack of agency for ECRs in leading aspects of their own research; gaining access to training opportunities in grantsmanship; and pressure to focus on producing only positive results of statistical significance. Proposed solutions to these problems point to particular aspects where training ECRs may be beneficial. These findings may be informative to the scientific community as we consider how to train ECRs for research independence.
\end{abstract}




\section{Introduction}

Early career researchers (ECRs, broadly graduate students and postdocs) should be well-positioned to drive science forward through learning how to carry out an independent research project (e.g. as a graduate student) and then begin crafting and managing their own independent research question under the mentorship of an independent investigator (e.g. as a postdoctoral researcher). However, the training of independent researchers in academia can be hindered by the fact that ECRs are also the primary labor force driving scientific research forward. In addition to conducting experiments, ECRs are involved in scholarly activities such as writing manuscripts and grants, preparing and presenting their work at national and international meetings, and engaging in manuscript peer review (McDowell et al. 2019). They are also under pressure to manage other aspects of research, including generating data and training new laboratory members. Furthermore, the productivity of an ECR affects their supervisor's research progress and career trajectory, which can take priority over their training. ECRs may therefore be left with little time to focus on generating their own novel research ideas for future publications and grants, which they can eventually take with them to start their own laboratories.

The issue of research independence in academia, and how researchers attain it, has been a topic of concern for some time. It was addressed extensively in the "Bridges to Independence" study by the National Academies of Sciences, Engineering and Medicine (NASEM), with authors of the subsequent report stating that:

"The definition of "independence" as a researcher in a tenure-track faculty position who has received his or her first $R 01$ research project grant is outdated...we define an 'independent investigator' as one who enjoys independence of thought" (National Research Council 2005).

One of the barriers to attaining an independent status highlighted by Ben Barres is the tension that many postdocs experience in terms of being supported by research project grants in order to fulfill the aims of someone else's research project (Barres 2017). This barrier prevents postdocs from fulfilling their goals of developing their own research independent research project and achieving important 
professional milestones. As Barres stated: "I think it's time for the academic community to start openly discussing the issue of research freedom for postdocs (or lack of it) (Barres 2017)."

To educate ECRs on current discussions about research independence and learn from their perspectives on these issues, we organized a series of workshops in the U.S. and Japan. The goals of these workshops were to:

- Inform ECRs of changing trends in the scientific enterprise and enable them to make informed career decisions;

- Initiate a discussion to help ECRs identify the barriers they face in research for independence and career growth;

- Facilitate a discussion to propose solutions based on specific training requirements for attaining independence in research; and

- Enable ECRs to take charge of their careers.

Here we present and discuss barriers perceived by ECRs to attaining research independence and potential solutions for overcoming them. Many barriers identified were related to focusing on training the individual researcher. Among them, imposter syndrome and developing confidence in their research abilities were recurring themes. Systemic barriers to research independence included: lack of access to professional development training; lack of funding mechanisms through which to develop independence; and lack of non-anecdotal data about the realities of succeeding in the academic system. Workshop participants felt that many of these factors contributed to the difficulty in establishing their own research independence. They identified actions which stakeholders (individuals, research groups, institutions and funding agencies) could take to help ECRs overcome these barriers, such as making a wide variety of training opportunities available to more of the ECR population, establishing multiple mentors, preparing ECRs for faculty job applications, as well as providing and requiring continued professional development for all researchers and faculty members. These proposals address the imbalance in the priorities of the research enterprise between maintaining productivity and providing a sustainable training environment for future generations of ECRs to reach their intellectual potential and utilize their talents to benefit society. 


\section{Methods}

Future of Research (FoR) organized four workshops on research independence for ECRs in different locations and at various types of institutions that employ graduate students and postdocs (Table 1).

\begin{tabular}{|c|c|c|c|}
\hline Institution & $\begin{array}{l}\text { Country } \\
\text { (workshop } \\
\text { year) }\end{array}$ & $\begin{array}{l}\text { Type of } \\
\text { institution }\end{array}$ & Title of workshop presentation \\
\hline University of Chicago & U.S. (2017) & Private & $\begin{array}{l}\frac{\text { Training transitions: From }}{\text { dependence to independence }^{*}} \\
\text { (McDowell 2017) }^{\text {McDow }}\end{array}$ \\
\hline$\underline{\text { University of Illinois at Chicago }}$ & U.S. (2017) & Public & $\begin{array}{l}\text { Training transitions: From } \\
\text { dependence to independence }^{*} \\
\text { (McDowell 2017) }^{\text {McDow }}\end{array}$ \\
\hline $\begin{array}{l}\text { Okinawa Institute of Science and } \\
\text { Technology Graduate University }\end{array}$ & Japan (2018) & Private & $\begin{array}{l}\text { Paving the road to independence } \\
\text { (McDowell 2018) }\end{array}$ \\
\hline University of California, Irvine & USA (2020) & Public & $\begin{array}{l}\text { Training transitions: Paths to } \\
\text { independence in research } \\
\text { (McDowell 2019) }\end{array}$ \\
\hline
\end{tabular}

Table 1. Future of Research workshops on research independence at institutions in the U.S. and Japan from 2017 to 2020. Links to slides are provided. ${ }^{*}$ These slide decks differed only in their title slide.

The workshops were targeted at and mostly attended by STEM, particularly biomedical, ECRs.

Background information was initially presented in the form of slides listing the issues and current challenges on ECRs attaining research independence from the perspective of Future of Research (Table 1). We then conducted an interactive session, during which participants identified barriers to achieving research independence and proposed solutions to overcome them. Each workshop ran for a total of ninety minutes. The number of participants at each session ranged from ten to fifty and included almost entirely, or an equal mix, of graduate students and postdocs, depending on the audience to whom the sessions were primarily advertised. We collected these data and obtained quotes from participants on both barriers and solutions proposed for each workshop. 


\section{Workshop Results \& Discussion}

The workshops generated many points of discussion through which participants identified common barriers in achieving research independence and professional academic career growth. Participants also identified solutions which different stakeholders could undertake to address these issues. Several of these barriers and solutions were raised repeatedly within and across workshops, and many common themes emerged out of the workshops. These were categorized into six broad areas (Tables 2 and 3 ). A categorized topic list of quotes from workshop participants is also available in the Supplementary Data Tables S1 $(A, B)$ to S4 $(A, B)$. Additionally, all the quotes collected from the workshops can be found in Supplementary Data Table S5. A summary of stakeholder-specific solutions proposed by workshop participants can be found in Supplementary Information 1. 


\section{Barriers identified by ECRs to achieving research independence}

The barriers identified by ECRs in the workshops highlight many common issues faced by this group of academics, including lack of independence in terms of research projects and ideas, lack of career training for roles outside of academia, lack of mentorship guidelines from funding agencies, the need to train faculty in mentorship, the variation in salaries among ECRs, and the lack of emphasis on work-life balance in academia. Additional barriers to independence exist for particular groups within the ECR population, which is diverse, for example foreign-born researchers working in U.S. laboratories in terms of eligibility for grants and fellowships (Table 2). 
Table 2. Barriers to research independence identified by ECRs during Future of Research workshops in the U.S. and Japan.

What barriers do ECRs face in achieving independence?

Independence is "discouraged"

- I'm not allowed to think about an independent project, design and conduct my own experiments, and it inhibits creativity

- No knowledge or guidance on how to transition into a PI role or how to train oneself to be an independent researchers

- Lack of incentives for independence

- My advisor doesn't give me enough independence to write and present data in my own style. Instead I have to follow his/her style of presentation format and writing style

Barriers faced by international scholars

- I'm scared, If I don't follow my PIs guidelines, I may lose my visa status

- Unavailability of grants as an international scholar

- Restrictions on grant eligibility

- Bias against immigrant researchers

- Work authorization/visa is restricted to academic institutions and industries are reluctant to hire international scholars and sponsor their visa
The paucity of career development data and resources

- Pls have tunnel vision for career \& close minded to career exploration

- No knowledge about career options, resources, training $\&$ support

- Graduate school does not provide opportunity to learn/show leadership skills

- I do not want to continue research as a career but interested in

communication/teaching. However, my advisor is unable to help me find those avenues to train for that career

Inadequate salaries and benefits

- Salary is not commensurate to the cost of living

- Duration of postdoc contracts vary

- Varying salaries depending on citizenship status, large vs small institutes, unionized vs non-unionized institutes

\section{No formal mentorship training}

- Students are not mentored properly until the final year when they are ready to graduate

- We are not trained to train new members/manage the lab, and also it is not listed as a requirement for work in the lab

- Don't have proper training structure

- Misalignment in ideas of training

- Micromanagement of schedule/projects

- Grants lack mentoring guidelines/plans

- Hands-off approach, no research training

- Pigeon-holes into roles

\section{Misalignment with academic system and} culture

- Imposter syndrome

- Comparison with others

- Bad work-life balance

- Overworked \& underpaid

- Sacrifice a lot to become an independent researchers, values, relationships, time, holidays 
Solutions proposed by ECRs to achieve research independence

The solutions proposed by ECRs in the workshops highlight many common ideas proposed across institutions to address various facets preventing them from achieving research independence. These include ECRs taking charge of their own careers, mandatory coursework for careers outside of academia, required mentorship training for supervisors, decreased exploitation of foreign-born ECRs based on visa status, higher salaries and improved benefits for ECRs, and a greater emphasis on work-life balance (Table 3). 
Table 3. Solutions for research independence proposed by ECRs during Future of Research workshops in the U.S. and Japan.

\begin{tabular}{|c|c|c|}
\hline \multicolumn{3}{|c|}{ What solutions do ECRs propose for achieving independence? } \\
\hline $\begin{array}{l}\text { Independence is "discouraged" } \\
\text { - Novel \& independent ideas should be } \\
\text { rewarded buy allowing ECRs to pursue } \\
\text { them as their own projects } \\
\text { - Rewards for independence \& independent } \\
\text { research projects should be provided by } \\
\text { granting agencies/independence awards } \\
\text { - Implement motivational grants to help } \\
\text { pursue novel ideas } \\
\text { - Transparency in research } \\
\text { - Incentives for independence } \\
\text { Postdocs should be allowed to take grants } \\
\text { with them if under certain circumstances } \\
\text { they have to move to a different } \\
\text { institution }\end{array}$ & $\begin{array}{l}\text { The paucity of career development data and } \\
\text { resources } \\
\text { - Provide more career development } \\
\text { resources and training } \\
\text { Mandatory class/course work for outside } \\
\text { academia careers } \\
\text { - Formalizing a curriculum for } \\
\text { communicating research } \\
\text { Mandatory Career development \& } \\
\text { - } \quad \text { Practical experience } \\
\text { - Opportunities should be provided to teach } \\
\text { and mentor young researchers }\end{array}$ & $\begin{array}{l}\text { No formal mentorship training } \\
\text { - PIs should be trained on how to mentor } \\
\text { - Mandatory mentoring training for mentors } \\
\text { - Mentor-mentee programs } \\
\text { mentorship grants to encourage good } \\
\text { - } \quad \text { Along with evaluating PIs based on their } \\
\text { productivity, they should also b evaluated } \\
\text { on the training they impart to ECRs \& } \\
\text { mentoring skills } \\
\text { ECRs should be make part of the } \\
\text { evaluation process }\end{array}$ \\
\hline $\begin{array}{l}\text { Barriers faced by international scholars } \\
\text { - Restrictions on grant eligibility for foreign } \\
\text { nationals should be relaxed } \\
\text { - PIs should not be allowed to exploit ECRs } \\
\text { based on their visa status - accountability } \\
\text { - Build peer-peer network for a sense of } \\
\text { community } \\
\text { - Keep track of changing policies on } \\
\text { immigration } \\
\text { - Immigration workshops on campus to make } \\
\text { international scholars aware about the visa } \\
\text { transition process }\end{array}$ & $\begin{array}{l}\text { nadequate salaries and benefits } \\
\text { (Stable contracts for a certain duration) } \\
\text { Increase in salary \& better benefits like } \\
\text { that of full-time employees } \\
\text { Longer appointments, so a postdoc is } \\
\text { considered as a job \& not just training }\end{array}$ & $\begin{array}{l}\text { Misalignment with academic system and } \\
\text { culture } \\
\text { - Institutes should ensure work-life balance } \\
\text { - Set clear \& practical expectations } \\
\text { - Project confidence } \\
\text { - Less judgement about work-life balance } \\
\text { - Don't be afraid to change the lab "culture" }\end{array}$ \\
\hline
\end{tabular}




\section{Themes Arising From the Workshops}

Most of the issues raised by ECRs in the workshops focused around six major themes. Here we discuss particular topics addressed within each of these themes, as well as current actions or recommendations that have been made by other stakeholders. We then discuss the concept of research independence: what it is currently understood to mean, what it perhaps should mean, and the extent to which it should be desired by academic researchers. Topics within these themes will be described in the context of NASEM reports related to training, mentorship, and the academic environment in general (National Research Council 2005; National Academies of Sciences, Engineering, and Medicine 2018a; National Academies of Sciences, Engineering, and Medicine 2018c; National Academies of Sciences, Engineering, and Medicine 2018b; National Academies of Sciences, Engineering, and Medicine 2019). Recommendations from these five reports relevant to this study are listed in Supplementary Information 2.

\section{Independence is "discouraged"}

The path towards a researcher's independence involves academic training while simultaneously developing a research topic of interest, in order to carve out a research niche and sustain their career trajectory. However, in the current academic system, the principal investigator may carry out most of the intellectual labor of generating ideas and writing grants, delegating much of the practical labor to ECRs, with the purpose of generating data to advance the laboratory's publications and grants. This division of intellectual vs practical labor prioritizes productivity towards the benefit of the laboratory, as well as the institution, while reducing the focus on fostering the research independence of ECRs.

Focusing on someone else's practical labor rather than their own intellectual labor may prevent ECRs from critically thinking about their own research ideas, and may reduce the intellectual conversation within the laboratory environment, especially if the division of labor becomes entirely intellectual on the part of the supervisor, and entirely practical on the part of the ECR. This situation exists in laboratories, as 
highlighted by workshop participant comments such as, "Lack of creativity to find new research directions"; "Pls are not ready to involve us in grant writing or project planning"; "No help with the project or intellectual freedom"; "Being worked as a tech without guidance or intellectual stimulation"; and "Pls are focused on tenureship by working hard or making trainees work hard instead of nurturing them to be future generation of independent scientists".

Lack of adequate training mechanisms to protect the time and individual research project development of ECRs is also a barrier to independence. Independent grants and fellowships could provide the protection of time and provision of resources to foster the research independence of ECRs. Most ECRs are funded on research project grants (National Institutes of Health n.d.) which support the labor of research, not training, leading to the issue of ECRs being unable to take independent projects with them (Barres 2017). However only a small number of these grants and fellowships are available to foreign-born researchers, with restrictions on applications. One of the participants recommended, "Rewards for independence and independent research projects should be provided by granting agencies or independence awards etc". Providing increased research funding for particular research areas may also be beneficial and others have suggested increasing the number of NIH Director's New Innovator (DP2) Awards (Alberts et al. 2018).

Women, minoritized researchers, and women from minoritized populations have a harder time gaining access to these and other grant opportunities (Ginther et al. 2011; Ginther et al. 2016; Pickett 2018). Some of these barriers may be attributable to implicit biases in academia (League of European Research Universities 2018), but also many of the issues identified are due to explicit, systemic biases (Hoppe et al. 2019).

In discussing solutions to this barrier, ECRs should keep track of the expectations from their supervisors, and be aware of the additional burdens placed upon them. The nuts and bolts of running a laboratory are often hidden from ECRs, and making these best practices more transparent could foster the professional transition of ECRs to running their own laboratory. It is therefore critical for them to find supervisors, and also mentors, who encourage both their own independence of thought and research ideas (The quest for postdoctoral independence, Nature 2018). Departments have a critical role to play in 
enhancing the research independence of ECRs employed by a particular institution, and should provide oversight and expectations for protecting their training and professional development.

Part of the issue is that many postdocs are working as de facto staff scientists, but providing the benefit of doing so cheaply on temporary contracts. With no formal requirements for completing postdoc training (compared to the dissertation requirements of graduate students), postdocs can be claimed as "trainees", with lower salary requirements due to these expectations. Postdocs can then perform an identical role to a staff researcher, but at a fraction of the cost. To this end, a discussion on the stability of staff positions took place, with participants suggesting, "Setting levels of postdocs e.g. Level I,II,III etc" (such as those in place at the Broad Institute (Hyman 2017)) and "Tenured researcher levels to be introduced to provide research independence, job security". One role for departments could be in providing different types of support and necessary structures for staff scientists. For example, we could imagine a scenario where a department provides financial support for staff scientists across laboratories, much as they would invest in core equipment. Various recommendations have been made that institutions invest in more staff scientist positions, with higher salaries and more stable positions for talented researchers who may not desire to start their own laboratories. The likely barrier to implementing more staff scientist roles, however, is that, while postdoc positions can be paid from grants, there is little incentive for an institution to pay for its own research staff, when research project grants can cover the cost of hiring postdocs.

Overall, in order to foster research independence for ECRs, a more formal and clear division between staff scientist roles, and training positions, including protected time and resources for training, is necessary.

\section{The paucity of career development data and resources}

In recent decades, the number of available tenure-track faculty positions in STEM has stagnated, while the number of PhDs awarded every year across multiple disciplines has increased (National 
Academies of Sciences, Engineering and Medicine 2007; Cyranoski et al. 2011; National Academies of Sciences, Engineering, and Medicine 2018a). In biomedicine, $30 \%$ of U.S. $\mathrm{PhD}$ recipients have committed to a postdoc position upon graduation, while $50 \%$ have no definite career plans (National Science Foundation 2014). Regardless, $\sim 80 \%$ of U.S. PhD recipients begin subsequent postdoc positions (Kahn and Ginther 2017) suggesting that a large number of graduate students default into postdoc positions. This concept is supported by data on postdoc outcomes from the Coalition for Next Generation Life Science ((CNGLS), https://nglscoalition.org/, (Blank et al. 2017)), indicating that across institutions, a quarter of postdoc positions are held for less than 1 year, and the median length of the postdoc is 2 years. While the majority of $\mathrm{PhD}$ students intend to stay in the academy following graduation (Sauermann and Roach 2012; Roach and Sauermann 2017), only $~ 50 \%$ of postdocs intend to do the same after their training (Gibbs et al. 2015). The hypercompetitive academic environment (Alberts et al. 2014) and glut of postdocs (Bourne 2013a) may lead ECRs to become 'permadocs': individuals doing multiple postdocs (a quarter leave their position to do another postdoc (CNGLS data)) in the hopes that one day they will be appointed as faculty members (Bourne 2013b; Powell 2015). Instead, the major destination for PhD degree holders in biomedicine is now non-academic, non-research positions (National Academies of Sciences, Engineering, and Medicine 2018c). These data point to an inefficiency in preparing the PhD workforce for both academic and non-academic careers.

ECRs present at our workshops seemed partially aware of the current state of the academic job market, and expressed unhappiness with the inadequate resources for professional development training opportunities for non-academic careers, as well as frustration with the inadequate awareness amongst advisors about careers outside of academia. "I do not want to continue research as a career and l'm interested in pursuing teaching/science communication. However, my advisor is unable to help me find those avenues or train for that career," and "Advisors unaware of career options other than the ones in academia" are two such representative ECR perspectives. Workshop participants expected their institutions to not only provide more avenues of career and professional development but also to continue increasing awareness about the importance of these programs amongst faculty and departments (Watts et al. 2019). 
Academic institutions excel at providing excellent subject matter training and help produce a large pool of PhDs in specialized fields of science, with vast technical knowledge and a good track record of academic publications. However, academic training does not translate into a workforce rich in independent thinking and professional skills, which are required to solve real world problems in society, pointing to a gap between the skills that $\mathrm{PhD}$ graduate hold and those required in the labor market (Mason et al. 2016; Bosch and Casadevall 2017; Bosch 2018). Participants stated they had "No training for non-academic jobs and therefore, ECRs feel less prepared/competitive for the job market".

To address this gap, incorporating professional skills into the academic training for ECRs - such as science communication, mentorship, leadership and business acumen - is necessary. Providing ECRs with such resources may decrease the phenomenon of students defaulting into postdoc positions and remaining in long, underpaid, overworked academic jobs when they could better utilize their talents elsewhere.

Some funding agencies are now moving towards prioritizing career development for ECRs. For example, the National Institute of General Medical Sciences (NIGMS) requires institutions to include a career and mentorship training plan in their T32 Training grant applications and reports. Also, through the Common Fund, NIH supported the Broadening Experiences in Scientific Training (BEST) pilot program, which funded professional development programs for ECRs at seventeen institutions across the country (Meyers et al. 2016).

In addition to building excellent professional development programs, it is also essential for ECRs to have faculty buy-in, allowing them to participate in these programs. However, many workshop participants reported the lack of encouragement by faculty for taking time out of the laboratory to attend career development events: "There is no support for exploring other careers". Indeed, when asking at the start of the workshops whether they had told their supervisors that they were participating in these sessions, few ECRs admitted to doing so, a phenomenon familiar to those providing professional development in the academy. ECRs should have the liberty to take charge of their own careers and the ability to regularly attend career development events on- and off-campus in order to enrich their training. 


\section{No formal mentorship training}

Academic training uses an apprenticeship model, where training for graduate students and postdocs is provided by supervisors who are further ahead in their careers. In the U.S., these supervisors are automatically referred to as "mentors". But while supervisors can be mentors, this is complicated by the supervisory employer-employee relationships in universities (Johnson 2007).

In order for both ECRs and faculty members to succeed in productive lab environments, workshop participants suggested that faculty should supplement their supervisory roles with required mentorship training, in order to ensure overall academic growth and research independence of their graduate students and postdocs. This practice has also been recommended elsewhere, in addition to calling for mentorship training tailored to each segment of an academic's career trajectory, specifically for anyone (e.g. graduate students, postdocs, junior and senior faculty) with supervisory roles in academia (National Academies of Sciences, Engineering, and Medicine 2019). However, a lack of institutional resources and specific career preparation programs that train the current, next and future generations of "mentors", combined with little to no requirement on their part for a demonstration of formal mentorship skills or commitments in hiring processes and grant applications, means that graduate students, postdocs and faculty members are expected to acquire mentorship skills by doing, not by learning. In practice, they must test and develop their own mentorship skills by experimenting on subsequent generations of researchers. Such experiments are dangerous. They can affect the career aspirations or trajectories of those in the mentoring relationship, and poor mentorship by anyone in a supervisory role should not be a determining factor for who gets to stay in the academy, an issue particularly affecting the retention of minoritized researchers (Layton et al. 2016).

With no formal requirements or oversight of mentorship ability, there is often no incentive for supervisors to be good mentors beyond their personal desire to act as such. Rather than an institutional or systemic solution, ECRs are often advised to take individual steps to solving this problem themselves, particularly in seeking out the best mentors in their departments or institutions. This practice is a poor solution, because these mentors are then more likely to become overwhelmed supervising other people's 
trainees while trying to run their own research groups. This could in fact hinder the career progression of good mentors, by requiring extra service of them without recognizing it, and actually further the careers of poor ones, who now spend less time on mentorship and more time on other aspects of managing their projects. Positive mentorship should be incentivized and rewarded, as recommended elsewhere (National Academies of Sciences, Engineering, and Medicine 2019).

In order to address these issues, participants discussed the need for ECRs to learn about reasonable expectations from their supervisors (which should be set ahead of time), as well as ways to effectively manage these expectations, in a process referred to as "mentoring up" or "managing up" (Lee 2016; Harvard Business Review Guides 2013). At the same time, ECRs can reflect on the experiences they have had in receiving mentorship, and seek out ways of becoming better mentors in turn to their own mentees, thereby actively developing their own mentorship skills in the academy.

Ensuring a chain of mentorship (that each mentor in turn has a mentor) would address some of the barriers that ECRs face to achieving research independence, by mitigating the uncertainty they experience at each career transition throughout their career progression. By providing training to ECRs on effective mentoring practices, and meaningful mentorship to new faculty, the career transition point into independent faculty positions could be more effectively managed by those who go through it, and more attractive to those otherwise put off by it. Given that the postdoc-to-faculty transition is one of two major checkpoints hindering diversification of the biomedical professoriate (Meyers et al. 2018), attention should be given to mentorship at this critical transition.

Workshop participants suggested including mentorship plans in grant applications supporting ECRs. This idea has also been recommended elsewhere (National Academies of Sciences, Engineering, and Medicine 2019; National Academies of Sciences, Engineering, and Medicine 2018a) and the National Science Foundation requires mentorship plans for postdoctoral fellowship applications (National Science Foundation 2009). Overall, research grants that do not provide plans for mentorship or training should be unable to support a mentee or trainee.

The considered, deliberate and evidence-based case for centering mentorship in academia has been made most recently (National Academies of Sciences, Engineering, and Medicine 2019), with 
resources provided at a dedicated site (https://www.nap.edu/resource/25568/interactive/). The Center for the Improvement of Mentored Experiences in Research (CIMERproject.org) and the National Research Mentoring Network (nrmnet.net) both have mentor training resources available, with all NRMN/CIMER mentor trainings including a specific module called "Fostering Independence".

\section{Barriers faced by international scholars}

The U.S. research enterprise is heavily dependent on labor from foreign-born researchers.

Indeed, Science and Engineering Masters and Doctorate degree level occupations in the U.S. are filled by foreign-born workers at the rate of $39 \%$ and $45 \%$, respectively (National Science Foundation 2018). The number of foreign-born researchers in the U.S. biomedical workforce has increased over the past 30 years, therefore the majority of the U.S. biomedical workforce is foreign-born (Heggeness et al. 2016; Heggeness et al. 2017). Two-thirds of U.S. postdocs are estimated to be foreign-born (Ferguson et al. 2017). Foreign-born scientists constitute $25 \%$ of tenure-track faculty roles in U.S. higher education and are first authors on 44\% of U.S. papers in science-related topics (Stephan 2010). While the U.S. research system benefits from this international flow of knowledge and personnel (Regets 2001) the nature of their immigration status can limit the ability to develop independence.

Participants at our workshops expressed concerns over the limited number of training mechanisms made available by U.S. funding agencies for international researchers. As a large number of faculty in the U.S. are foreign-born (Stephan 2010), funding agencies are actively preventing future U.S. faculty who carry out graduate studies of postdoctoral research in the U.S. access to training. Workshop participants proposed that funding agencies should ease restrictions on eligibility requirements for international researchers. There is no known legal barrier to doing so. For example, the NIH's Career Development $(\mathrm{K})$ awards are at the control of the NIH Director, under authority granted by the Public Health Service Act, and have no citizenship restrictions. The National Research Service (F and T) Awards are governed by the 1974 National Research Act, and no citizenship restrictions are stipulated within the Act. Indeed, the existence of exceptions to this policy in the K99/R00, F99/K00, and F05 mechanisms are 
testament to the ability of NIH to open training mechanisms to foreign-born researchers, should they wish to do so.

International researchers who are funded on research project grants, and with their visa status tied to their supervisors, are placed in a position of extreme power imbalance. One of the participants from the workshop stated, "I'm scared that if I don't follow my PIs guidelines, I may lose my visa status". The exploitation of foreign-born ECRs, illustrating the position of power that supervisors have over them, was recently documented and discussed extensively (Stephan 2013; Nature Editorial Board 2018; Hayter and Parker 2018). Participants expected that institutions should do more to protect international scholars and have a clearly defined policy when it comes to visa sponsorship by supervisors, as well as duration and early visa termination which, for example in the case of a J1 visa, can result in a postdoc being required to fly back to their home country the same day as their position is terminated. This situation can also result in foreign-born researchers being expected to work for lower wages. Indeed, U.S.-residing full-time employed $\mathrm{PhD}$ scientists and engineers on temporary visas receive significantly lower salaries compared with their native born counterparts (National Science Foundation 2017). This is reflected in an analysis of $\mathrm{NIH}$ intramural postdoctoral salaries in 2016 and 2017, where international researchers were paid less than U.S. citizens and permanent residents (Gary McDowell, data not shown).

International researchers who complete their STEM PhDs in the U.S. on an F visa are allowed to work in the U.S. upon completion of their degree for a brief duration in academic or industry settings (Department of Homeland Security n.d.). However recipients of foreign PhD degrees, who come to the U.S. to pursue postdoctoral research, are placed on more restrictive visas, such as the J1 exchange visitor/Research Scholar Program (Department of State 2005) or H1B skilled worker (United States Citizenship and Immigration Services n.d.) visas. Foreign-born PhDs interested in working in industry settings are restricted by the limited number of $\mathrm{H}-1 \mathrm{~B}$ visas available for the for-profit sector $(\mathrm{H}-1 \mathrm{~B}$ visas for non-profit organizations, such as universities, are unlimited, and also do not have to meet the same salary requirements (U.S. government Publishing Office 2018)). Therefore, the only option for foreign-born researchers is to stay in the academy until they can build the case for permanent residency. 
This fact is illustrated by a recent analysis showing that having temporary residency status is the strongest determining factor in pursuing a postdoc position within 3 years of $\mathrm{PhD}$ completion in the US (Kahn and Ginther 2017). Industries, especially startup firms, experience greater difficulty securing visas for highly skilled workers, thereby constraining the ability of technology startups to tap into a growing segment of the STEM PhD workforce (National Academies of Sciences, Engineering, and Medicine 2015). As workshop participants stated, "Work authorization/visa is restricted to academic institutions and industries are reluctant to hire international scholars and sponsor their visa." The hiring process for a foreign-born $\mathrm{PhD}$ into a for-profit company requires a visa processing fee, time, and uncertainty due to the lottery system. The cost to sponsor a visa can number tens of thousands of dollars for both attorney and filing fees, and takes several months, which can be prohibitive for resource-constrained companies (Roach 2017; Roach and Skrentny 2019).

Immigration issues affect many ECRs in the U.S. research enterprise, and add significant extra burdens to their ability to attain research independence. This contributes to a weakening of the workforce within our institutions, and the creation of a workforce less able to benefit society.

\section{Inadequate salaries and benefits}

A major problem faced by ECRs towards attaining research independence is the inadequate provision of salaries and benefits. which can prevent them from being able to afford to stay in academic training positions. Workshop participants quoted, "Low postdoc salaries" and "Small paychecks" as barriers to independence. Salaries for postdocs, for example, vary across the U.S. and do not take into account cost of living (Woolston 2017). In addition, university bureaucracies struggle to identify and administer postdocs, with the large number of titles and designations leading to confusion in postdoc classifications both within and across institutions (Schaller et al. 2017). This fact causes issues in identifying postdocs within institutions (Pickett et al. 2017) and therefore ensuring that institutional salary policies (Ferguson et al. 2017) are actually being enforced. While the median postdoc salary in 2016 matched the NIH NRSA minimum Year 0 stipend, there was a wide range of salaries and a postdoc 
gender pay inequity in the Northeast and South U.S. Census regions (Athanasiadou et al. 2018). This is a solvable problem for the academic community, combined with repeated recommendations that postdoc salaries should be raised to a level that incorporates cost-of-living, years of experience, and actively avoids pay inequities in the system (National Academies of Sciences, Engineering and Medicine 2014; National Academies of Sciences, Engineering, and Medicine 2018c; Greider et al. 2019). This problem could also be approached by placing more ECRs, including foreign-born researchers, on training awards rather than on research project grants.

Better peer-to-peer information sharing at the ECR level was suggested in the workshops. To this end, resources for sharing graduate school stipends (http://www.phdstipends.com/), postdoc salaries (https://postdocsalaries.com/) and benefits (http://bostonpostdocs.org/advocacy/benefits, (Cijsouw et al. 2017)) are examples of ways to increase awareness of these issues more broadly. Institutional actions such as publishing standard salary guidelines, and increasing transparency on postdoc salary data (for example, publishing aggregate data to ensure no gender pay inequity exists) were also recommended in our sessions. To this point, we would also emphasize the need to ensure that such guidelines are enforced; many exist (Ferguson et al. 2017) but the individual hiring of postdocs and lack of institutional oversight means that adherence to such rules is highly variable (Athanasiadou et al. 2018).

Finally at the federal level, discrepancies in postdoc salaries arise based on whether ECRs are paid from training grants or faculty research project grants, such as from $\mathrm{NIH}$. Confusion on this point has existed for many years as to employee vs. trainee status for postdocs, with widespread reporting of the loss of employee benefits, such as childcare and healthcare, when a researcher moves from being "staff" on a research project grant to a "trainee" on a training grant (Ferguson et al. 2017). Clarity from funding agencies, or adjustments at institutions to circumvent this problem, are recommended. In our own work at Future of Research, institutions have insisted that it is illegal to provide benefits to trainees, and NIH officials have insisted that no such legal barriers exist. We can only recommend that several stakeholders establish the reality of the situation and resolve it for the betterment of ECRs. 


\section{Misalignment with academic system and culture}

In the current hypercompetitive research environment, work-life balance for ECRs is often not prioritized, despite its importance for maintaining a healthy and productive academic system. While work-life balance is often difficult to achieve in general, for academics it can be even more difficult to do so due to the demanding nature of this work, and the incentive structures that exist in this hypercompetitive environment (Alberts et al. 2014; Edwards and Roy 2017). Recent studies have shown that mental health issues are on the rise among $\mathrm{PhD}$ students, and work-life balance satisfaction for this population has also been declining (Bleasdale 2019; Evans et al. 2018; Loissel 2019; Krause and Harris 2019; Levecque et al. 2017; The Graduate Assembly 2014; Nagy et al. 2019). The NASEM are currently conducting a study of the ways in which colleges and universities provide treatment and support for the mental health and well-being of undergraduate and graduate students, with a focus on STEMM students (https://www.nationalacademies.org/our-work/supporting-the-whole-student-mental-health-and-well-beingin-stemm-undergraduate-and-graduate-education). ECRs are also taking the matter into their own hands, by starting several initiatives (such as https://www.phdbalance.com/ and the http://dragonflymentalhealth.com/) to raise awareness on these issues and advocate for improved academic mental health policies. It is important to point out that a focus on mental health and well-being is not only necessary for ECRs, but also at other levels in academia, including faculty (Lashuel 2020).

Our workshops showed that ECRs could benefit from peer-to-peer support networks, as well as clearly delineated working hours and time off. At the level of departments and institutes, it would be necessary to improve research practices allowing for healthy working habits, in order to prevent exploitation of the time that ECRs can put into their work, as well as mitigate academic burnout (Cannizzo et al. 2019). Funding agencies also have a role to play in terms of incentivizing work-life balance and placing a stronger focus on mental health as part of fellowship and grant applications.

Whether work-life balance for academics can actually be achieved is a difficult thing to assess (Gould 2014; Owens et al. 2018), especially for those who not only have to balance mental wellness but also other responsibilities (e.g. parenting, being a caregiver, or researching while black (Nzinga-Johnson 
2013; De Welde and Stepnick 2015; Hardy et al. 2016; Antecol et al. 2018)). Overall, the theme of work-life balance is central to the issues discussed above, such as financial insecurity and inadequate mentorship, and critical to maintaining a healthy and productive research enterprise.

\section{Concluding Thoughts}

\section{Suggested Actions for Stakeholders}

In Table 4, we summarize recommended actions for different stakeholders in order to foster research independence for ECRs: ECRs themselves; faculty; departments; institutions; scientific societies, funding agencies and government.

\section{Rethinking and Fostering "Independence"}

To understand the broader context underlying struggles that ECRs face in achieving research independence, it is necessary to discuss the current hypercompetitive academic environment, which is particularly acute in the biomedical sciences (Alberts et al. 2014). The scientific enterprise and workforce are heavily dependent on fluctuating trends in the funding environment (Teitelbaum 2014; Hur et al. 2015; Hur et al. 2017), and it is in this hypercompetitive and unstable funding scenario that attempts to maximize the amount of research output at minimal cost are made.

The practical labor of STEM research is carried out by ECRs such as graduate students and postdocs. The number of PhD degrees awarded in the biomedical sciences in the U.S. has increased over the past 3 decades (National Science Foundation n.d.) and consistently $80 \%$ of graduates go on to do a postdoc (Kahn and Ginther 2017), many as a default (Sauermann and Roach 2016), leading to an increase in the number of academic postdocs in these disciplines. Across all fields, the number of tenure-track faculty positions has not increased (National Academies of Sciences, Engineering and Medicine 2007), and indeed much faculty hiring is currently frozen due to effects of the Covid-19 pandemic (Chemjobber 2020). Postdocs are particularly in a bind (Park 2020), because most of them 
want academic faculty positions, but they also recognize that there are few to be had, and they are incentivized to focus on research outputs and productivity, the metrics used in faculty hiring and grant success, and away from the professional development skills needed to succeed in all career positions, and yet are not required in faculty hiring (van der Weijden et al. 2016; Nowell et al. 2020).

Despite the critical importance of research independence to the advancement of a sustainable research enterprise, focus on this issue is stifled in the current academic system, which by tradition broadly and incorrectly equates career stage with competency across all domains of scientific pursuit. For example, ECRs, even those late into their postdoctoral years, are unable to submit research grants as Principal Investigators. Among many journals, there is a practice of excluding postdocs from officially peer reviewing manuscripts, yet it is common for PIs to delegate peer review to ECRs as 'training,' while providing neither credit nor any actual training to them (McDowell et al. 2019). While some may argue that the requirement for a postdoc to become faculty is due to the need for training and preparation towards becoming independent, two facts remain: 1) There are no available data to support the claim that postdoctoral positions provide or support intentional training to postdocs in identified core competencies towards a faculty position, and 2) a postdoc was optional in the 1960s, and indeed one third of postdocs receiving training 1969 were actually on a sabbatical from a tenure-track faculty position (NRC 1969)). In other words, the goalpost has moved not because of a need for training, but because of competition for jobs.

he academic system must shift away from a decreased reliance on temporary trainees and hypercompetition towards a sustainable postdoc workforce (Ålund et al. 2020), with an increased reliance on resource-sharing and more permanent staff positions. This shift will require a change in the definition of "research independence" (National Research Council 2005) to be more inclusive of the various groups engaged in performing bench science, the multiple roles that ECRs play in the enterprise, the diverse funding mechanisms through they may be compensated, and the broader systemic changes necessary to foster independence in a collaborative research environment. In order to take these factors into account, a proposed all-encompassing definition of an independent researcher could be "a researcher involved in generating scientific ideas with freedom of thought and designing and conducting experiments 
to test them". In addition to performing bench science, researchers need to be afforded the opportunity to further develop their own independence of thought. This shift would allow researchers to not only demonstrate the value of their own work in a variety of settings, but also to participate as a team member in a larger vision of the laboratory, the department, or the institution. This culture change may therefore ultimately foster a more collaborative mindset for researchers, with each individual bringing their strengths to the collective, helping the system advance more effectively.

Fostering independence of thought for ECRs within a collaborative environment will be important not only for facilitating their ability to develop independent directions for their own laboratory, but will also for designing a more efficient way for the research enterprise to function as a whole. The current "race-to-bottom" of competition for financial and professional resources in academia, rather than resource-sharing across laboratories during this time of funding scarcity, does not lead to a sustainable system. A shift in the culture of science towards a practice where collaboration and creativity are valued over individual gain to the PI may incentivize researchers who may otherwise leave academia because of a misalignment of personal values with those of the academy (Gibbs and Griffin 2013).

Finally, it is important to consider that not all academic researchers desire to become "independent" in terms of research (but may desire to become independent thinkers), and likewise "independence" should not be so prized a quality in academia that it disincentivizes collaboration and participation in team science within laboratories. It may instead be necessary to consider the concept of "agency" in research which may be different from "independence" itself, again addressing our proposed revision of the term "independent researcher" above. For an ECR, agency could manifest as a certain degree of freedom to pursue research directions within a larger context of the laboratory, in a setting where team science is encouraged, and which may involve decoupling various roles from the "independent investigator" function, instead redistributing labor appropriately across multiple members of a laboratory or research group. This model provides a way to envision multiple research roles that advance the academic enterprise besides the traditional faculty. Fostering agency is also important for advancing the aspirations of ECRs interested in industry (Roach and Sauermann 2010; Roach and 
Sauermann 2017), as well as other sectors outside of the academy, therefore building a stronger scientific workforce which can effectively influence society. 
Table 4. Stakeholder-specific recommendations to enhance research independence proposed by ECRs during Future of Research workshops in U.S. and Japan.

\section{Stakeholder-specific recommendations}

\begin{tabular}{|c|c|}
\hline $\begin{array}{l}\text { ECRs } \\
\text { - } \quad \text { Keep track of PIs expectations } \\
\text { - } \quad \text { Find a good mentor who encourages independence } \\
\text { - } \quad \text { Peer-peer networks } \\
\text { - } \quad \text { Attend career \& professional development events, on-campus \& } \\
\text { - } \quad \text { Stf-campus } \\
\text { - } \quad \text { Be aware of changing landscape of immigration rules \& keep } \\
\text { - } \quad \text { Keep track of NIH salary scales for postdocs } \\
\text { - } \quad \text { Clearly lay out working hours \& time off with the PI } \\
\text { - Keep an open dialogue with PI } \\
\text { - Seek mental health resources available on campus }\end{array}$ & $\begin{array}{l}\text { Pls/Research Groups } \\
\text { - } \quad \text { Mentors should be mentored } \\
\text { - } \quad \text { Focused mentoring } \\
\text { - } \quad \text { Allow independence in writing grants/fellowships } \\
\text { - } \quad \text { Provide career development opportunities } \\
\text { - } \quad \text { Include professional development courses in to core graduate } \\
\text { - } \quad \text { Jobriculum (also open to postdocs) } \\
\text { - } \quad \text { Transparity for postdocs by providing staff scientist positions } \\
\text { - } \quad \text { Clearly outlined policies for visa sponsorship, } \\
\text { - } \quad \text { Standard guidelines should be in place for postdoc salaries \& benefits } \\
\text { - } \quad \text { Ensure healthy work habits }\end{array}$ \\
\hline
\end{tabular}

Funding Agencies

- Provide incentives to grantees for providing independence to their trainees

- Relaxing restrictions of grants for international scholars

- Postdocs should be allowed to take their grants with themselves

- Grants should provide money for supporting career development programming

- Good mentoring plan should be incentivized during grant review process

- Mentor-mentee programs should be encouraged

- Relaxed restriction on kind of grants available for international scholars

- Visa sponsorship fee should be included in all the awarded grants

- Mental health programming should be mandatory at grant applicant institutions

- Support "the whole scientist" training instead of research specific

- Transparency \& accountability for harassment \& bullying by PIs 


\section{Declaration of Interests/Conflicts of Interest}

Gary McDowell carried out this work while working at The Future of Research, Inc. GM now works at Lightoller LLC, a sole-proprietor consultancy providing expertise on early career researchers.

Harinder Singh contributed towards organizing the workshops while at the University of Illinois at Chicago and then at the University of California Irvine. The data collected for this publication do not represent the views of either of the institutions presented but are only extrapolations of responses given by early career researchers at these institutions. These workshops were conducted in his capacity as a member of the Board of Directors at The Future of Research.

Adriana Bankston is an employee of the University of California Federal Governmental Relations (UC FGR) Office in Washington, D.C. Adriana contributed to this publication as a member of the Board of Directors at The Future of Research, and not through the University of California. In addition, this publication represents Adriana's personal views, and not the views of her employer, the University of California.

\section{Acknowledgments}

We would like to thank all the workshop participants for their input, Lauren Lyon from UC Irvine's Division of Career Pathways for facilitating the workshop at UCl, Sina Safayi, PhD, Founding Director of Career Development and Industry Outreach at Rush University and Brendan Delaney of Frank \& Delaney Immigation Law, LLC for reviewing the section on barriers faced by international scholars (immigration), and Juan Pablo Ruiz, PhD and Stephanie Davis, PhD for reviewing and editing this manuscript.

\section{Grant Information}

GM was supported by a grant from the Open Philanthropy Project. 


\section{Bibliography}

Alberts, B., Hyman, T., Pickett, C.L., Tilghman, S. and Varmus, H. 2018. Improving support for young biomedical scientists. Science 360(6390), pp. 716-718.

Alberts, B., Kirschner, M.W., Tilghman, S. and Varmus, H. 2014. Rescuing US biomedical research from its systemic flaws. Proceedings of the National Academy of Sciences of the United States of America 111(16), pp. 5773-5777.

Ålund, M., Emery, N., Jarrett, B.J.M., et al. 2020. Academic ecosystems must evolve to support a sustainable postdoc workforce. Nature Ecology \& Evolution 4(6), pp. 777-781.

Antecol, H., Bedard, K. and Stearns, J. 2018. Equal but Inequitable: Who Benefits from Gender-Neutral Tenure Clock Stopping Policies? American Economic Review 108(9), pp. 2420-2441.

Athanasiadou, R., McDowell, G.S., Bankston, A., Carlisle, M. and Niziolek, C.A. 2018. Assessing the landscape of US postdoctoral salaries. Studies in Graduate and Postdoctoral Education 9(2), pp. 213-242.

Barres, B.A. 2017. Stop blocking postdocs' paths to success. Nature 548(7669), pp. 517-519.

Blank, R., Daniels, R.J., Gilliland, G., et al. 2017. A new data effort to inform career choices in biomedicine. Science 358(6369), pp. 1388-1389.

Bleasdale, B. 2019. Researchers pay the cost of research. Nature Materials 18(8), pp. 772-772.

Bosch, G. 2018. Train PhD students to be thinkers not just specialists. Nature 554(7692), p. 277.

Bosch, G. and Casadevall, A. 2017. Graduate biomedical science education needs a new philosophy. mBio 8(6).

Bourne, H.R. 2013a. A fair deal for PhD students and postdocs. eLife 2, p. e01139.

Bourne, H.R. 2013b. The writing on the wall. eLife 2, p. e00642.

Cannizzo, F., Mauri, C. and Osbaldiston, N. 2019. Moral barriers between work/Life balance policy and practice in academia. Journal of cultural economy, pp. 1-14.

Chemjobber 2020. Want a faculty position? Get ready to wait. C\&EN Global Enterprise 98(18), pp. 37-37.

Cijsouw, T., Murali, S., Dykstra, S. and Otto, T. 2017. The perks of being a postdoc in Boston: creating transparency in the benefits landscape. F1000Research.

Cyranoski, D., Gilbert, N., Ledford, H., Nayar, A. and Yahia, M. 2011. Education: The PhD factory. Nature 472(7343), pp. 276-279.

Department of Homeland Security STEM OPT | Study in the States [Online]. Available at: https://studyinthestates.dhs.gov/stem-opt-hub [Accessed: 18 June 2020].

Department of State 2005. Code of Federal Regulations 22 CFR § 62.20 - Professors and research scholars.

De Welde, K. and Stepnick, A. 2015. Disrupting the culture of silence: Confronting gender inequality and making change in higher education. First. Sterling, Virginia: Stylus Pub.

Edwards, M.A. and Roy, S. 2017. Academic research in the 21st century: maintaining scientific integrity in a climate of perverse incentives and hypercompetition. Environmental engineering science 34(1), pp.

51-61. 
Evans, T.M., Bira, L., Gastelum, J.B., Weiss, L.T. and Vanderford, N.L. 2018. Evidence for a mental health crisis in graduate education. Nature Biotechnology 36(3), pp. 282-284.

Ferguson, K., McTighe, M., Amlani, B. and Costello, T. 2017. National Postdoctoral Association Institutional Policy Report 2017: Supporting the Needs of Postdocs. Rockville, MD: National Postdoctoral Association.

Gibbs, K.D. and Griffin, K.A. 2013. What do I want to be with my PhD? The roles of personal values and structural dynamics in shaping the career interests of recent biomedical science PhD graduates. CBE life sciences education 12(4), pp. 711-723.

Gibbs, K.D., McGready, J. and Griffin, K. 2015. Career Development among American Biomedical Postdocs. CBE life sciences education 14(4), p. ar44.

Ginther, D.K., Kahn, S. and Schaffer, W.T. 2016. Gender, race/ethnicity, and national institutes of health R01 research awards: is there evidence of a double bind for women of color? Academic Medicine 91(8), pp. 1098-1107.

Ginther, D.K., Schaffer, W.T., Schnell, J., et al. 2011. Race, ethnicity, and NIH research awards. Science 333(6045), pp. 1015-1019.

Gould, J. 2014. How do you achieve work/life balance in academia? [Online]. Available at: http://blogs.nature.com/naturejobs/2014/11/04/how-do-you-achieve-worklife-balance-in-academia/ [Accessed: 2 June 2020].

Greider, C.W., Sheltzer, J.M., Cantalupo, N.C., et al. 2019. Increasing gender diversity in the STEM research workforce. Science 366(6466), pp. 692-695.

Hardy, A., McDonald, J., Guijt, R., et al. 2016. Academic parenting: work-family conflict and strategies across child age, disciplines and career level. Studies in Higher Education 43(4), pp. 1-19.

Harvard Business Review Guides 2013. HBR guide to managing up and across: build relationships herd cats gain influence. Boston, Mass: Harvard Business Review Press.

Hayter, C.S. and Parker, M.A. 2018. Factors that influence the transition of university postdocs to non-academic scientific careers: An exploratory study. Research Policy 48(3), pp. 556-570.

Heggeness, M.L., Gunsalus, K.T.W., Pacas, J. and McDowell, G. 2017. The new face of US science. Nature 541(7635), pp. 21-23.

Heggeness, M., Gunsalus, K., Pacas, J. and McDowell, G. 2016. Preparing for the 21st Century Biomedical Research Job Market: Using Census Data to Inform Policy and Career Decision-Making Version 1. Self-Journals of Science.

Hoppe, T.A., Litovitz, A., Willis, K.A., et al. 2019. Topic choice contributes to the lower rate of NIH awards to African-American/black scientists. Science Advances 5(10), p. eaaw7238.

Hur, H., Andalib, M.A., Maurer, J.A., Hawley, J.D. and Ghaffarzadegan, N. 2017. Recent trends in the U.S. Behavioral and Social Sciences Research (BSSR) workforce. Plos One 12(2), p. e0170887.

Hur, H., Ghaffarzadegan, N. and Hawley, J. 2015. Effects of government spending on research workforce development: evidence from biomedical postdoctoral researchers. Plos One 10(5), p. e0124928.

Hyman, S. 2017. Biology needs more staff scientists. Nature 545(7654), pp. 283-284.

Johnson, W.B. 2007. Transformational supervision: When supervisors mentor. Professional Psychology: Research and Practice 38(3), pp. 259-267.

Kahn, S. and Ginther, D.K. 2017. The impact of postdoctoral training on early careers in biomedicine. 
Nature Biotechnology 35(1), pp. 90-94.

Krause, L.A. and Harris, S.L. 2019. Get online to support wellbeing of graduate students. eLife 8.

Lashuel, H.A. 2020. What about faculty? eLife 9.

Layton, R.L., Brandt, P.D., Freeman, A.M., Harrell, J.R., Hall, J.D. and Sinche, M. 2016. Diversity Exiting the Academy: Influential Factors for the Career Choice of Well-Represented and Underrepresented Minority Scientists. CBE life sciences education 15(3).

League of European Research Universities 2018. Implicit bias in academia: A challenge to the meritocratic principle and to women's careers - And what to do about it. LERU.

Lee, S. 2016. Mentoring Up.

Levecque, K., Anseel, F., De Beuckelaer, A., Van der Heyden, J. and Gisle, L. 2017. Work organization and mental health problems in PhD students. Research Policy 46(4), pp. 868-879.

Loissel, E. 2019. A question of support. eLife 8.

Mason, J.L., Johnston, E., Berndt, S., Segal, K., Lei, M. and Wiest, J.S. 2016. Labor and skills gap analysis of the biomedical research workforce. The FASEB Journal 30(8), pp. 2673-2683.

McDowell, G.S., Knutsen, J.D., Graham, J.M., Oelker, S.K. and Lijek, R.S. 2019. Co-reviewing and ghostwriting by early-career researchers in the peer review of manuscripts. eLife 8, p. e48425.

McDowell, G. 2018. Paving the road to independence. F1000Research.

McDowell, G. 2017. Training transitions: From dependence to independence. F1000Research.

McDowell, G. 2019. Training transitions: paths to independence in research. F1000 Research Limited.

Meyers, F.J., Mathur, A., Fuhrmann, C.N., et al. 2016. The origin and implementation of the Broadening Experiences in Scientific Training programs: an NIH common fund initiative. The FASEB Journal 30(2), pp. 507-514.

Meyers, L.C., Brown, A.M., Moneta-Koehler, L. and Chalkley, R. 2018. Survey of checkpoints along the pathway to diverse biomedical research faculty. Plos One 13(1), p. e0190606.

Nagy, G.A., Fang, C.M., Hish, A.J., et al. 2019. Burnout and mental health problems in biomedical doctoral students. CBE life sciences education 18(2), p. ar27.

National Academies of Sciences, Engineering, and Medicine 2018a. Graduate STEM education for the 21st century. Leshner, A. and Scherer, A. eds. Washington, D.C.: National Academies Press.

National Academies of Sciences, Engineering, and Medicine 2015. Immigration policy and the search for skilled workers: summary of a workshop. Cohen, G., Coulthurst, A., and Alper, J. eds. Washington, D.C.: National Academies Press.

National Academies of Sciences, Engineering, and Medicine 2018b. Sexual harassment of women: climate, culture, and consequences in academic sciences, engineering, and medicine. Benya, F. F., Widnall, S. E., and Johnson, P. A. eds. Washington (DC): National Academies Press (US).

National Academies of Sciences, Engineering, and Medicine 2018c. The next generation of biomedical and behavioral sciences researchers: breaking through. Beninson, L. and Daniels, R. eds. Washington (DC): National Academies Press (US).

National Academies of Sciences, Engineering, and Medicine 2019. The science of effective mentorship in STEMM. Dahlberg, M. L. and Byars-Winston, A. eds. Washington (DC): National Academies Press (US). 
National Academies of Sciences, Engineering and Medicine 2007. Rising above the gathering storm: energizing and employing america for a brighter economic future. Washington, D.C.: National Academies Press.

National Academies of Sciences, Engineering and Medicine 2014. The postdoctoral experience revisited. Washington (DC): National Academies Press (US).

National Institutes of Health NIH Data Book - National Statistics on Postdoctorates [Online]. Available at: https://report.nih.gov/nihdatabook/category/21 [Accessed: 4 June 2020].

National Research Council 2005. Bridges to Independence: Fostering the Independence of New Investigators in Biomedical Research. Washington (DC): National Academies Press (US).

National Science Foundation 2017. Doctorate Recipients from U.S. Universities: 2017 [Online]. Available at: https://ncses.nsf.gov/pubs/nsf19301/data [Accessed: 4 June 2020].

National Science Foundation 2009. Grant Proposal Guide Chapter II - Proposal Preparation Instructions [Online]. Available at: https://www.nsf.gov/pubs/policydocs/pappguide/nsf09_29/gpg_2.jsp [Accessed: 8 April 2018].

National Science Foundation 2018. Science \& Engineering Indicators 2018 [Online]. Available at: https://www.nsf.gov/statistics/2018/nsb20181/report/sections/science-and-engineering-labor-force/immigr ation-and-the-s-e-workforce [Accessed: 4 June 2020].

National Science Foundation 2014. Science and Engineering Indicators 2014 [Online]. Available at: https://www.nsf.gov/statistics/seind14/content/etc/nsb1401.pdf [Accessed: 14 July 2017].

National Science Foundation Survey of Doctorate Recipients (SDR) [Online]. Available at: http://www.nsf.gov/statistics/srvydoctoratework/ [Accessed: 9 July 2016].

Nature Editorial Board 2018. Stop exploitation of foreign postdocs in the United States. Nature 563(7732), p. 444.

Nowell, L., Ovie, G., Kenny, N. and Jacobsen, M. 2020. Postdoctoral scholars' perspectives about professional learning and development: a concurrent mixed-methods study. Palgrave communications 6(1), p. 95.

NRC 1969. Invisible University: Postdoctoral Education in the United States. Report of a Study Conducted Under the Auspices of the National Research Council. [Richard B. Curtis, Study Director]. Washington, D.C.: National Academies Press.

Nzinga-Johnson, S. 2013. Laboring Positions: Black Women, Mothering and the Academy. Demeter Press.

Owens, J., Kottwitz, C., Tiedt, J. and Ramirez, J. 2018. Strategies to Attain Faculty Work-Life Balance. Building Healthy Academic Communities 2(2).

Park, D.S. 2020. The Invisible University Is COVID-19 Positive. Trends in Genetics.

Pickett, C. 2018. Examining the distribution of K99/R00 awards by race [Online]. Available at: http://rescuingbiomedicalresearch.org/blog/examining-distribution-k99r00-awards-race/ [Accessed: 5 June 2020].

Pickett, C., Bankston, A. and McDowell, G.S. 2017. The GSS is an unreliable indicator of biological sciences postdoc population trends. BioRxiv.

Powell, K. 2015. The future of the postdoc. Nature 520(7546), pp. 144-147.

Regets, M. 2001. Research and Policy Issues in High-Skilled International Migration: A Perspective with 
Data from the United States. Social Science Research Network.

Roach, M. 2017. Encouraging entrepreneurship in university labs: Research activities, research outputs, and early doctorate careers. Plos One 12(2), p. e0170444.

Roach, M. and Sauermann, H. 2010. A taste for science? PhD scientists' academic orientation and self-selection into research careers in industry. Research Policy 39(3), pp. 422-434.

Roach, M. and Sauermann, H. 2017. The declining interest in an academic career. Plos One 12(9), p. e0184130.

Roach, M. and Skrentny, J. 2019. Why foreign STEM PhDs are unlikely to work for US technology startups. Proceedings of the National Academy of Sciences of the United States of America 116(34), pp. 16805-16810.

Sauermann, H. and Roach, M. 2012. Science PhD career preferences: levels, changes, and advisor encouragement. Plos One 7(5), p. e36307.

Sauermann, H. and Roach, M. 2016. SCIENTIFIC WORKFORCE. Why pursue the postdoc path? Science 352(6286), pp. 663-664.

Schaller, M.D., McDowell, G., Porter, A., et al. 2017. What's in a name? eLife 6, p. e32437.

Stephan, P.E. 2010. The "I"s Have It: Immigration and Innovation, the Perspective from Academe. Innovation Policy and the Economy 10, pp. 83-127.

Stephan, P. 2013. How to Exploit Postdocs. Bioscience 63(4), pp. 245-246.

Teitelbaum, M.S. 2014. Falling behind? Boom, Bust, and the Global Race for Scientific Talent. Princeton: Princeton University Press.

The Graduate Assembly 2014. Graduate Student Happiness \& Well-Being Report. Berkeley, CA: University of California Berkeley.

U.S. government Publishing Office 2018. Title 20 - EDUCATION; CHAPTER 28 - HIGHER EDUCATION RESOURCES AND STUDENT ASSISTANCE; SUBCHAPTER I - GENERAL PROVISIONS; Part A Definitions Sec. 1001 - General definition of institution of higher education.

United States Citizenship and Immigration Services H-1B Specialty Occupations, DOD Cooperative Research and Development Project Workers, and Fashion Models [Online]. Available at: https://www.uscis.gov/working-united-states/temporary-workers/h-1b-specialty-occupations-dod-cooperati ve-research-and-development-project-workers-and-fashion-models [Accessed: 4 June 2020].

Watts, S.W., Chatterjee, D., Rojewski, J.W., et al. 2019. Faculty perceptions and knowledge of career development of trainees in biomedical science: What do we (think we) know? Plos One 14(1), p. e0210189.

van der Weijden, I., Teelken, C., de Boer, M. and Drost, M. 2016. Career satisfaction of postdoctoral researchers in relation to their expectations for the future. Higher Education 72(1), pp. 25-40.

Woolston, C. 2017. Pay for US postdocs varies wildly by institution. Nature 551(7679), pp. 150-151. 


\section{Supplementary Data}

Supplementary Table S1A. Barriers faced by ECRs to achieve independence - University of Chicago (2017).

Supplementary Table S1B. Solutions identified by ECRs to achieve independence - University of Chicago (2017).

Supplementary Table S2A. Barriers faced by ECRs to achieve independence - University of Illinois at Chicago (2017).

Supplementary Table S2B. Solutions proposed by ECRs to achieve independence - University of Illinois at Chicago (2017).

Supplementary Table S3A. Barriers faced by ECRs to achieve independence - Okinawa Institute of Science and Technology Graduate University (2018).

Supplementary Table S3B. Solutions proposed by ECRs to achieve independence - Okinawa Institute of Science and Technology Graduate University (2018).

Supplementary Table S4A. Barriers faced by ECRs to achieve independence - University of California, Irvine (2020).

Supplementary Table S4B. Solutions proposed by ECRs to achieve independence - University of California, Irvine (2020).

Supplementary Table S5A. Raw data of all barriers faced, and solutions proposed, by ECRs at the University of Chicago.

Supplementary Table S5B. Raw data of all barriers faced, and solutions proposed, by ECRs at the University of Illinois Chicago.

Supplementary Table S5C. Raw data of all barriers faced, and solutions proposed, by ECRs during workshops at the Okinawa Institute for Science and Technology (2018).

Supplementary Table S5D. Raw data of all barriers faced, and solutions proposed, by ECRs during workshops at the University of California Irvine (2018).

Supplementary Information 1. Stakeholder-specific detailed solutions proposed by ECRs to achieve independence from both U.S. and Japan workshops.

Supplementary Information 2. Relevant recommendations from blue-ribbon panel reports 
Lack of knowledge about career options, resources, training and support

"Advisors unaware of career options other than

the ones in academia"

"Lack of resources for outside academia jobs or postings"

"No training for non-academic jobs and

therefore, ECRs feel less prepared/competitive

for the job market"

"There is no support for exploring other careers"

\section{No support for independence}

"No support available to transition into

independence. No knowledge or guidance on

how to transition into a $\mathrm{PI}$ role or how to train

oneself to be an independent researcher"

"No experience working outside of the lab. The

idea of working independently is scary"

"Lack skills outside of conducting research,

manuscript and grant writing"

\section{Lack of time}

think and plan for long term career goals"

"System is designed to expect outcome and not novelty"
"Too busy doing present work and no time to

\section{No job security}

"Postdoc position terms are dependent on the advisor's grant period. Once grant ends, postdocs have to look for another postdoc job"
Immigration status/rules

"Work authorization/

visa is restricted to academic institutions and industries are reluctant to hire international scholars and sponsor their visa"

"Unable to write many

grants/fellowships because most of them are for citizens"

\section{Advisors/PI's need workers and not} thinkers

"ECRs are supposed to or encouraged to work hard on a predefined project and no encouragement/reward for initiating/running new projects"

"PIs select trainees who are hard workers to move their project forward, in order for them to write manuscripts and grants, and no incentive for independent thinking"

"One sided power during training period"

"Micromanagement by PIs"

"Ideas by ECRs are not taken seriously"

Poor interpersonal skills and lack of conflict resolution resources

"Sometimes advisors are not courteous in delegating responsibilities, thanking for good work or offering rewards in terms of appreciation, resulting in stressful situations in the lab"

"Advisors are not trained in resolving conflicts between lab members, resulting in further deterioration of the lab environment" "Lack of respect for young researchers"

\section{Misalignment in ideas of training}

"Advisor's idea of training is to train for academic jobs, however ECRs require comprehensive and diverse training"

"More faculty members are needed who realize the importance of non-academic training" "Pls are not greatest career mentors"

"Competition between training and productivity you can either undergo training or be productive"

\section{Advisors are under intense pressure to} perform

"Advisors/PIs are focused on tenureship by working hard or making trainees work hard instead of nurturing them to be future generation of independent scientists" "Lack of institutional commitment to prevent hypercompetitiveness amongst PIs for survival. The ECRs bear the brunt of PIs stress"

\section{Lack of collaborative} environment

"Too much focus on independent work and collaborations are not encouraged"

"The majority of researchers avoid collaborations because they are territorial in their ideas/projects, which

\section{Funding guidelines/}

\section{mechanisms}

"Most of the funding agencies have time limits on writing grants for postdocs"

"The original purpose of lots of grants is to support novel ideas, however, grants do not get funded if there is not enough preliminary data"

"Many grant agencies require your PI to be a co-investigator on early career researcher's grants and if you move out of the lab, you have to surrender the grant resulting in lack of independence" ensures survival"

\section{Lack of training structure}

"Graduate students are not final year when they are supposed to graduate" "Not encouraged to take time off to attend career development events/ courses" mentored properly until the 
Supplementary Table S1B. Solutions identified by ECRs to achieve independence - University of Chicago workshops (2017).

\begin{tabular}{|c|c|c|c|}
\hline $\begin{array}{l}\text { Duration of postdoc contracts and salary } \\
\text { "Longer appointments so the postdoc is considered } \\
\text { as a job and not just training" } \\
\text { "Increase in salary and better benefits like those of } \\
\text { full time employees" }\end{array}$ & $\begin{array}{l}\text { More non-academic jobs training } \\
\text { "Provide more non-academic career } \\
\text { training" } \\
\text { "Make non-academic careers less scary } \\
\text { by providing resources and } \\
\text { classes/courses for it" } \\
\text { "Support ECRs by allowing industry } \\
\text { internships, time away from lab" }\end{array}$ & $\begin{array}{l}\text { Independent project ideas } \\
\text { should be encouraged } \\
\text { "Novel and independent ideas } \\
\text { should be rewarded by allowing } \\
\text { ECRs to pursue them as their own } \\
\text { projects" }\end{array}$ & $\begin{array}{l}\text { Goal setting for postdocs } \\
\text { "Setting levels of postdocs e.g.Level I,II,III } \\
\text { etc" } \\
\text { "Tenured researcher levels to be } \\
\text { introduced to provide research } \\
\text { independence, job security" } \\
\text { "Mid-goals position for postdocs before } \\
\text { they become Pls to allow for a smooth } \\
\text { transition" }\end{array}$ \\
\hline $\begin{array}{l}\text { Restrictions on grant eligibility should be } \\
\text { relaxed } \\
\text { "Number of years spent as postdocs to be eligible for } \\
\text { writing grants should be increased" } \\
\text { "International scholars/non-citizens should be } \\
\text { allowed to write the majority of the grants, after all } \\
\text { they work in same capacity as citizen scientists" } \\
\text { "Postdocs should be allowed to take grants with } \\
\text { them if under certain circumstances they have to } \\
\text { move to a different institution" }\end{array}$ & $\begin{array}{l}\text { Collaborative science } \\
\text { "Culture of collaboration compared to } \\
\text { individual science should be encouraged } \\
\text { and rewarded" } \\
\text { "Collaborative grants with multiple } \\
\text { researchers should be encouraged and } \\
\text { become more of a norm" }\end{array}$ & $\begin{array}{l}\text { Mentoring networks } \\
\text { "Networking between ECRs } \\
\text { (co-mentoring) should be built to } \\
\text { provide support to each other" }\end{array}$ & $\begin{array}{l}\text { Incentives for independence } \\
\text { "Rewards for independence and } \\
\text { independent research projects should be } \\
\text { provided by granting agencies or } \\
\text { independence awards" } \\
\text { "Implement motivational grants to help } \\
\text { pursue novel ideas" }\end{array}$ \\
\hline $\begin{array}{l}\text { Mentoring for mentors and ECRs } \\
\text { "PIs should be trained on how to mentor" } \\
\text { "ECRs should be provided training on how to mentor } \\
\text { new members in the lab" } \\
\text { "Mentorship grants to encourage good mentorship } \\
\text { among PIs" }\end{array}$ & $\begin{array}{l}\text { Encourage hiring young faculty } \\
\text { "Seasoned researchers should retire to } \\
\text { make space for young researchers with } \\
\text { fresh new ideas" }\end{array}$ & $\begin{array}{l}\text { Grant structure } \\
\text { "Change overhead costs/indirect } \\
\text { costs to lower burden on Pls so } \\
\text { they pay postdocs well" }\end{array}$ & $\begin{array}{l}\text { Comprehensive evaluation of PIs for } \\
\text { tenure } \\
\text { "Along with evaluating PIs based on their } \\
\text { productivity, they should also be } \\
\text { evaluated on the training they impart to } \\
\text { ECRs and mentorship skills" } \\
\text { "ECRs should be made part of the } \\
\text { evaluation process" }\end{array}$ \\
\hline
\end{tabular}




\begin{tabular}{|c|c|c|c|}
\hline $\begin{array}{l}\text { Expectations in terms of time, effort and } \\
\text { requirements to graduate (graduate } \\
\text { students), responsibilities other than } \\
\text { research (postdocs) are not specified } \\
\text { "Along with doing experiments, ECRs are } \\
\text { expected to train new members in the lab, } \\
\text { which is done on their own research time } \\
\text { and is not rewarded" } \\
\text { "We are not trained to train new members/ } \\
\text { manage the lab, and also it is not listed as a } \\
\text { requirement for work in the lab" }\end{array}$ & $\begin{array}{l}\text { Lack of defined responsibilities and } \\
\text { guidelines } \\
\text { "My advisor makes me work in his/her grant, } \\
\text { reviewing manuscripts for them and sometimes } \\
\text { preparing their slides for talks" } \\
\text { "I'm scared to say 'NO', otherwise my } \\
\text { graduation may be delayed or I will get a bad } \\
\text { recommendation letter. This allows my advisor } \\
\text { to add extra work on me" }\end{array}$ & $\begin{array}{l}\text { Micromanagement } \\
\text { "My advisor doesn't allow me to } \\
\text { have my own schedule of working } \\
\text { and managing projects according to } \\
\text { my capacity" }\end{array}$ & $\begin{array}{l}\text { Preventing ECRs from developing } \\
\text { their own style of disseminating } \\
\text { science } \\
\text { "My advisor doesn't give me enough } \\
\text { independence to write and present data } \\
\text { in my own style. Instead I have to follow } \\
\text { his/her style of presentation format and } \\
\text { writing style" }\end{array}$ \\
\hline $\begin{array}{l}\text { Lack of knowledge amongst advisors } \\
\text { about other careers emanating out of } \\
\text { academic training } \\
\text { "I do not want to continue research as a } \\
\text { career and l'm interested in pursuing } \\
\text { teaching/science communication. However, } \\
\text { my advisor is unable to help me find those } \\
\text { avenues to train for that career" }\end{array}$ & $\begin{array}{l}\text { Mentors are not trained to mentor } \\
\text { "My mentor is not very good at mentoring and } \\
\text { therefore it results in uncomfortable and } \\
\text { stressful situations" } \\
\text { "I'm asked to mentor undergraduate students, } \\
\text { graduate students in lab but I have no training } \\
\text { in mentoring" }\end{array}$ & $\begin{array}{l}\text { Not allowed to attend } \\
\text { conferences of their choice } \\
\text { "My advisor doesn't let me go to } \\
\text { conferences other than the ones } \\
\text { she/he goes to" } \\
\text { "National Postdoc Association } \\
\text { annual meetings are considered } \\
\text { non-scientific, therefore I have to } \\
\text { pay myself" }\end{array}$ & $\begin{array}{l}\text { Balancing guidance/direction with } \\
\text { independence } \\
\text { "It is difficult to be independent without } \\
\text { guidance, however, my advisor's } \\
\text { guidance/ directions make be } \\
\text { dependent" }\end{array}$ \\
\hline $\begin{array}{l}\text { Pressure and competition } \\
\text { "There's pressure from my advisor and } \\
\text { competition amongst my peers, which } \\
\text { prevents me from enjoying science by } \\
\text { generating ideas and being independent" }\end{array}$ & $\begin{array}{l}\text { Lack of Independence of ideas } \\
\text { "I'm not allowed to think about an independent } \\
\text { project, design and conduct my own } \\
\text { experiments, as it inhibits creativity" }\end{array}$ & $\begin{array}{l}\text { Lack of uniformity in structure } \\
\text { "There is too much structure in the } \\
\text { lab. My advisor's style of mentoring } \\
\text { is too much hands on" } \\
\text { "There's no structure in my } \\
\text { lab/training. My advisor's style of } \\
\text { mentoring is very hands off" }\end{array}$ & $\begin{array}{l}\text { Immigration status } \\
\text { "I'm scared if I don't follow my PIs } \\
\text { guidelines, I may lose my visa status" } \\
\text { "Unavailability of grants as an } \\
\text { international scholar" }\end{array}$ \\
\hline
\end{tabular}


Supplementary Table S2B. Solutions proposed by ECRs to achieve independence - University of Illinois at Chicago workshops (2017).

\begin{tabular}{|c|c|c|c|}
\hline $\begin{array}{l}\text { Uniform guidelines } \\
\text { "Graduate and postdoctoral } \\
\text { training should be } \\
\text { standardized" } \\
\text { "Well-defined expectations/ } \\
\text { responsibilities and should } \\
\text { be strictly followed" }\end{array}$ & $\begin{array}{l}\text { Formalizing a curriculum for communicating } \\
\text { research } \\
\text { "A formal training course should be designed and } \\
\text { incorporated into the graduate curriculum to train } \\
\text { them in communicating science" } \\
\text { "Postdocs come from a different lab (graduate } \\
\text { school) and adapt to a new lab style, therefore, their } \\
\text { skills and training should be used to train graduate } \\
\text { students in presenting their science in presentations. } \\
\text { This will further help in providing researchers } \\
\text { independence of thought and expressing their ideas } \\
\text { in their own style, an important step in skill set } \\
\text { development for the future in nurturing creativity" }\end{array}$ & $\begin{array}{l}\text { Early career education (Undergraduate to } \\
\text { early graduate school) } \\
\text { "More resources for career development - } \\
\text { career development training" } \\
\text { "Mandatory class/ } \\
\text { coursework for other careers" }\end{array}$ & $\begin{array}{l}\text { Focused mentorship } \\
\text { "Say 'No' to non-project related } \\
\text { assignments" } \\
\text { "Prioritize your own work and then lab } \\
\text { managing or advisor's work" }\end{array}$ \\
\hline $\begin{array}{l}\text { Mandatory training for } \\
\text { trainees } \\
\text { "Funding agencies should } \\
\text { enforce training requirement } \\
\text { for trainees e.g. attending } \\
\text { career development and } \\
\text { networking conferences" }\end{array}$ & $\begin{array}{l}\text { Practical experience } \\
\text { "Practical experience should be provided to trainees } \\
\text { so they can make informed decisions about careers } \\
\text { such as industry careers" }\end{array}$ & $\begin{array}{l}\text { Encourage flexibility } \\
\text { "Advisors should be more accepting of } \\
\text { thoughts/ } \\
\text { ideas from ECRs" }\end{array}$ & $\begin{array}{l}\text { No category } \\
\text { "Do your own research/ footwork; } \\
\text { institutional regulations to reign in } \\
\text { advisors" }\end{array}$ \\
\hline $\begin{array}{l}\text { Mentor-mentee programs } \\
\text { "Graduate student } \\
\text { associations and Postdoc } \\
\text { associations should focus on } \\
\text { these programs" }\end{array}$ & $\begin{array}{l}\text { Building a strong network system } \\
\text { "A peer network should be formed to share, discuss, } \\
\text { explore avenues for career growth" }\end{array}$ & & \\
\hline
\end{tabular}


Supplementary Table S3A. Barriers faced by ECRs to achieving independence - Okinawa Institute of Science and Technology Graduate University workshops (2018).

\begin{tabular}{|c|c|c|c|}
\hline $\begin{array}{l}\text { Not trained to say 'NO' } \\
\text { "It is difficult to say 'NO' to my advisor } \\
\text { when more work is given" }\end{array}$ & $\begin{array}{l}\text { Lack of training in how to manage } \\
\text { time and train people in science } \\
\text { "Not trained on managing time and } \\
\text { prioritizing projects" } \\
\text { "No training on how to manage } \\
\text { (mentor?) new members" } \\
\text { "No training on how to manage } \\
\text { finances (?)" }\end{array}$ & $\begin{array}{l}\text { Lack of time and } \\
\text { resources } \\
\text { "Not enough time to } \\
\text { focus on career } \\
\text { development and lack } \\
\text { of avenues for future } \\
\text { career growth" }\end{array}$ & $\begin{array}{l}\text { No independent projects } \\
\text { "Working on a project, which was started by someone else before } \\
\text { me. No opportunity to design my own project" } \\
\text { "PI dictates the project" }\end{array}$ \\
\hline $\begin{array}{l}\text { Differences in independence based o } \\
\text { Pls funding } \\
\text { "Old lab had low funds, therefore, less } \\
\text { independence" }\end{array}$ & & & \\
\hline
\end{tabular}


Supplementary Table S3B. Solutions proposed by ECRs to achieve independence - Okinawa Institute of Science and Technology Graduate University workshops (2018).

\begin{tabular}{|c|c|c|c|}
\hline Keep track of Pls expectations & $\begin{array}{l}\text { Deal with it } \\
\text { "Communicate with others } \\
\text { about systems and structures" }\end{array}$ & $\begin{array}{l}\text { Keep expectations and outcomes } \\
\text { clear } \\
\text { "Make it clear to your PI that researchers } \\
\text { working on a project with take it with } \\
\text { them to be independent in their future } \\
\text { career" }\end{array}$ & $\begin{array}{l}\text { More career development opportunities } \\
\text { "Opportunities should be provided to teach and mentor } \\
\text { young researchers" }\end{array}$ \\
\hline $\begin{array}{l}\text { More avenues and opportunities to } \\
\text { apply for independent } \\
\text { grants/fellowships } \\
\text { "Pls should encourage ECRs to apply } \\
\text { for their own grants for independence" }\end{array}$ & $\begin{array}{l}\text { Identifying skills you can } \\
\text { learn from an institution }\end{array}$ & $\begin{array}{l}\text { Communicate and form a community } \\
\text { "Share with peers and form support } \\
\text { groups to help with career progress" } \\
\text { "Team building and set up } \\
\text { collaborations" }\end{array}$ & $\begin{array}{l}\text { Take charge of your career and proactively seek other } \\
\text { opportunities } \\
\text { "Plan what kind of career you want in the next 5-10 years" }\end{array}$ \\
\hline $\begin{array}{l}\text { Transparency in the funding } \\
\text { process }\end{array}$ & $\begin{array}{l}\text { Keep communication lines } \\
\text { open with your PI } \\
\text { "Be open and keep updating } \\
\text { the PI about your career } \\
\text { needs and see if they can } \\
\text { help" }\end{array}$ & & \\
\hline
\end{tabular}


Supplementary Table S4A. Barriers faced by ECRs to achieving independence - University of California, Irvine workshops (2020).

\begin{tabular}{|c|c|c|c|}
\hline $\begin{array}{l}\text { Lack of equal opportunities for international scholars } \\
\text { "Limited availability of grants as foreign researchers" } \\
\text { "Bias against immigrant researchers" } \\
\text { "More grants for citizens and more restrictions for } \\
\text { international scholars" }\end{array}$ & $\begin{array}{l}\text { Decreased funding for } \\
\text { research } \\
\text { "Lack of enough money" } \\
\text { "Internal money dictates } \\
\text { research" } \\
\text { "Lack of resources" } \\
\text { "Limited funding resources } \\
\text { to draw from" } \\
\text { "Limited resources - } \\
\text { instruments" } \\
\text { "Lack of funding to do your } \\
\text { own research" }\end{array}$ & $\begin{array}{l}\text { Low salaries } \\
\text { "Low postdoc } \\
\text { salaries" } \\
\text { "Small paychecks" }\end{array}$ & $\begin{array}{l}\text { Abysmal mentoring and lack of training } \\
\text { "Unrealistic expectations" } \\
\text { "Bad training/mentoring" } \\
\text { "Lack of training to identify good research paths to follow" } \\
\text { "Lack of training on time management" } \\
\text { "Lack of responsiveness from Pl" } \\
\text { "No communication with Pl" } \\
\text { "Lack of communication between faculty and trainees" } \\
\text { "Not helpful with all the managerial and regulatory tasks" } \\
\text { "No training for non-research responsibilities" } \\
\text { "Lack of role models" } \\
\text { "Hands-off approach, no research training" } \\
\text { "Pigeon holes into roles" }\end{array}$ \\
\hline $\begin{array}{l}\text { Lack of independence in research, publications and } \\
\text { pursuing grant ideas } \\
\text { "Not allowed to take project with me (sabotage)" } \\
\text { "Delaying publications to secure grants" } \\
\text { "Evil PI coercion (Do this or get fired)" } \\
\text { "Putting multiple lab members on the same project and } \\
\text { then the taking data away from all but only one for } \\
\text { publication" } \\
\text { "Lack of independence" } \\
\text { "PI is not ready to involve you in grant writing or project } \\
\text { planning" } \\
\text { "Luck in research project" } \\
\text { "Networking for grant money - double blind" } \\
\text { "Bo help with the project or intellectual freedom" } \\
\text { stimulation" } \\
\text { "Lack of creativity to find new research directions" }\end{array}$ & $\begin{array}{l}\text { Involvement in } \\
\text { non-research activities } \\
\text { "No money for tech or lab } \\
\text { managers and therefore } \\
\text { end up doing extra jobs on } \\
\text { top of grad/postdoc } \\
\text { research" } \\
\text { "Too many undergrads to } \\
\text { supervise, no training to } \\
\text { read and write" } \\
\text { "Too much workload" } \\
\text { "Not working on own } \\
\text { paper - unethical } \\
\text { incentives" }\end{array}$ & $\begin{array}{l}\text { Non-collaborative } \\
\text { strategy } \\
\text { "Academic politics" } \\
\text { "Lack of willingness } \\
\text { to collaborate and } \\
\text { interact with other } \\
\text { researchers and } \\
\text { groups" }\end{array}$ & $\begin{array}{l}\text { Playing it safe } \\
\text { "Delaying publications to secure grants" } \\
\text { "Taking care of oneself during a high expectation environment" } \\
\text { "Research tunnel vision" }\end{array}$ \\
\hline $\begin{array}{l}\text { Career \& professional development } \\
\text { "Pls have tunnel vision for career" } \\
\text { "Close minded to career exploration" }\end{array}$ & $\begin{array}{l}\text { Imposter syndrome } \\
\text { "I'm not good enough" } \\
\text { "Comparison with others" }\end{array}$ & $\begin{array}{l}\text { Bad work-life } \\
\text { balance } \\
\text { "Sacrifice a lot to } \\
\text { become an } \\
\text { independent } \\
\text { researcher, values, } \\
\text { relationships, time, } \\
\text { holidays" }\end{array}$ & \\
\hline
\end{tabular}


Supplementary Table S4B. Solutions proposed by ECRs to achieve independence - University of California, Irvine workshops (2020).

\begin{tabular}{|l|l|l|}
\hline $\begin{array}{l}\text { PI with better mentoring skills } \\
\text { "Find good Pl" } \\
\text { "PI with better management skills" } \\
\text { "Find PI/mentor who has your best } \\
\text { interests in mind e.g. allows } \\
\text { intellectual development" } \\
\text { "Reach out to find other mentors, } \\
\text { other than your PI" } \\
\text { "Find a mentoring team" } \\
\text { "Find alternative sources of } \\
\text { mentoring" }\end{array}$ & $\begin{array}{l}\text { Focus on broader skills development } \\
\text { during training } \\
\text { "Networking" } \\
\text { "Being informed about what careers are } \\
\text { there for PhDs, besides academic" } \\
\text { "Support groups" }\end{array}$ & $\begin{array}{l}\text { Focus on aspects other than scientific training } \\
\text { "Communication skills training" } \\
\text { "Networking" } \\
\text { "Prioritize workload" } \\
\text { "Set short term goals" } \\
\text { "Ignore your problems" } \\
\text { "Figuring out what you don't know, so you can learn it" } \\
\text { "Prepare for faculty job applications" } \\
\text { "Attend more career and professional development events at UC Irvine" } \\
\text { "Join professional organizations" }\end{array}$ \\
\hline $\begin{array}{l}\text { Maintain work-life balance } \\
\text { "Treat imposter syndrome" } \\
\text { "Projecting confidence" } \\
\text { "Less judgement about work-life } \\
\text { balance" } \\
\text { "Don't be afraid to change the lab } \\
\text { culture" }\end{array}$ & $\begin{array}{l}\text { Transparency in research } \\
\text { "Anonymity while complaining" } \\
\text { "Treat not like tech" } \\
\text { "More protection for postdocs" } \\
\text { "Salary commensurate to cost of living" }\end{array}$ & $\begin{array}{l}\text { Funding and efficient use of resources } \\
\text { "Utilize available resources" }\end{array}$ \\
\hline
\end{tabular}


Supplementary Table S5A. Raw data of all barriers faced, and solutions proposed, by ECRs during workshops at the University of Chicago (2017).

\begin{tabular}{|c|c|}
\hline University of Chicago: $n=50$ & University of Chicago: $n=50$ \\
\hline Barriers & Solutions \\
\hline Group 1 & Group 1 \\
\hline Knowing what career options exist & Make non-academic jobs less scary \\
\hline Time to think and plan long term & Longer appointments/contracts \\
\hline Authority to spend money & Higher pay/more savings \\
\hline Job security & Have a good idea. Sell it to your PI. Preferably offshoot/related \\
\hline \multicolumn{2}{|l|}{ Recognition within lab } \\
\hline \multicolumn{2}{|l|}{ Immigration status/rules } \\
\hline \multicolumn{2}{|l|}{ Mobility within US } \\
\hline \multicolumn{2}{|l|}{ Standard job offers/database } \\
\hline \multicolumn{2}{|l|}{ Feeling unprepared, competitive } \\
\hline Group 2 & Group 2 \\
\hline PI funding mechanisms don't support trainee independence & Intermediate goals, stepping stones for postdocs (Level I, II, etc) \\
\hline \multicolumn{2}{|l|}{ PI selection is for most perseverant, not necessarily best } \\
\hline \multicolumn{2}{|l|}{ PIs lack incentive for producing independent trainee - no direct benefits } \\
\hline \multicolumn{2}{|l|}{ Lack of support for transition to full independence } \\
\hline \multicolumn{2}{|l|}{ Not enough incentives for Pls to support a transition to independence } \\
\hline \multicolumn{2}{|l|}{$\begin{array}{l}\text { Fight for survival for Pls - not enough time and energies and resources to mentor, } \\
\text { support or even allow more independence }\end{array}$} \\
\hline \multicolumn{2}{|l|}{$\begin{array}{l}\text { Stable funding: soft money dependency/instability, flat competitive environment; } \\
\text { Lack of institutional commitment; Fight for survival }\end{array}$} \\
\hline \multicolumn{2}{|l|}{ Pressure on Pls; less energy/time for training; no incentives -> less independence } \\
\hline \multicolumn{2}{|l|}{ System requires people to execute only } \\
\hline $\begin{array}{l}\text { Too much focused on individuals vs collaboration (as in Europe) - it's a deeply } \\
\text { rooted cultural feature in US that becomes a problem }\end{array}$ & \\
\hline
\end{tabular}




\section{Group 3}

Dependence on mentor $\$$ for ideas

Not all research is equal: time/quick; field/relevance

Salary is covered by fellowship; no supply $\$$ - not true independence!

Choice in appropriate research field $\& \$$; passion vs practice

Sensitive to racial tensions

Few fellowships for international postdocs

Time at position excludes you from grants e.g. K99/R00

Money/field is expensive

\section{Group 4}

PI Support for Independence

Funding for independent ideas

Additional training

\section{Group 5}

\section{Self-belief/confidence}

Money

Pre-existing project

PI

Knowledge

Competency

Politics

Time

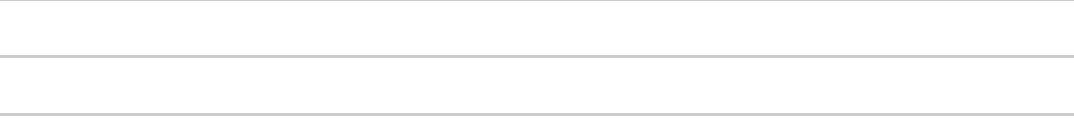

\section{Group 3}

Break down monopolies [edit - relates to money/field is expensive]

Extend to 6 years [edit - relates to K99/R00]

New president; more $\$$; country of origin sponsorship [edit - relates to international postdoc opportunities]

Mid-goals position before PI within the postdoc period (junior, senior...as in France, see CNRS)

Tenured researcher position (level I, II, etc) as in France

More grants for transition than just $\mathrm{K} 99$, with longer eligibility than 4 years from $\mathrm{PhD}$ - maybe another for up to 7 years or 10 years from the $\mathrm{PhD}$ (see ERC)

Collaborative grants to support a less individualistic culture (see Europe)

\section{Group 4}

Mentoring Network

Co-mentoring

Financial support for independence

\section{Group 5}

Protected time for career development

Implement small motivation grants to help people pursue new ideas

Training for Pls

Independent source of wealth

Change tenure requirements to broaden beyond grants and papers

Better mentorship

Change indirect costs to free up more grant money

Change cultural expectations around postdoc

Change tenure to open up new spots for young researchers

Involve trainees in tenure evaluations

Clearer path to tenure

Less restrictive grant funding 


\section{Group 6}

Poor conflict resolution in academia

Need more faculty who realize that not everyone wants to be faculty

$\mathrm{PI}$ micromanagement of projects

Default is a postdoc

No negatives for mentor for poor mentorship

Competition between training and productivity

Misalignment between what PI thinks training is vs what you need as trainee

Lack skills outside of research and grant writing

Resist spending time outside of lab on career development

Ideas not taken as seriously as you'd like by advisor

Pls are not the greatest career mentors

Lack of respect for young investigators

Power is one-sided during training time

Out of eligibility for funding

Lack experience outside of the lab

\section{Group 7}

Lack of a structured plan - everything left for the last year

Lack of support from PI for postdocs interested in non-academic careers

Power over postdoc careers resides with PIs and institutions and is driven by

their priorities, not with organizations who have postdocs career interests in

minds (i.e. postdoc associations)

Developing independent project to take with you (structure for this?)

\section{Group 6}

Grant money to support grad/student postdoc to do internship

Integrate fellowship into graduate training other career training

All grad students will have time to do an internship

Mentorship training for faculty/importance of development programs for trainees

Remove the stigma [edit - over non-academic careers]

\section{Group 7}

Grant money for mentoring 
Supplementary Table S5B. Raw data of all barriers faced, and solutions proposed, by ECRs during workshops at the University of Illinois Chicago (2017).

University of Illinois at Chicago: $\mathbf{n}=\mathbf{2 0}$

University of Illinois at Chicago: $n=20$

\section{Barriers}

\section{Micromanagement and a lack of time}

High expectations and a multitasking - not prepared for enough

Micromanagement of ideas; Not allowed to be creative/independent ideas Publishing and writing grants = "yard stick" of productivity; science $->$ microfocus in terms of ideas, advisor-specific grants/ideas

Science communication; restricted style of writing, presentation and creative art work Lack of time to complete research \& take advantage of other opportunities

(externships, conferences etc)

Lack of career guidance

Lack of publications

Prove yourself - how?

Inability to attend conferences

Lack of support/guidance/training

How do I do my job?

Postdoc [position] doesn't cultivate independence

Chicken/egg question: balancing direction/guidance with independence

Publication bias - new idea every week

Pressure from the top, competition, at all levels

Structure - too much? too little?

Lack of training with different respects: for example: a practical training in industry

(co-op/internship)

Independence in science - advisor/PI research ideas to be followed by grad student;

Independence in scientific writing

\section{Solutions}

Early career education (undergrad to early grad)

Training or teaching programs in science communications, presentations -> need to nurture creativity

More resources for career development - grad curriculum should have career development training

Mandating class/course work for other careers

Defined expectations

Learning how to say no

Support for taking trainees to conferences; help shape interactions

Practical industry training for careers (industry careers)

Encourage flexibility and thoughts/ideas from grad students; increase resources for grad students wrt careers in academia and industry

Do your own research/footwork; institutional regulations to reign in Pls

Strong network; Effective guidance

More focused mentorship

More training/more diverse training

Find a great mentor match, but how? \{Make mentor accountable?\}

"DGS" helpful - formal postdoc graduate student mentor-mentee

Protected time: - own work - Pls work

More reviewer training opportunities for junior people to review 
Supplementary Table S5C. Raw data of all barriers faced, and solutions proposed, by ECRs during workshops at the Okinawa Institute for Science and Technology (2018).

\section{Okinawa Institute of Science and Technology: $n=10$}

\section{Barriers}

It's difficult to say 'no' to PI

Expectation of independence - difference in funding systems - old lab, very low on funds

Fellowship application: timing vs learning

Feeling the urge to find new position when the one you are in just started due to postdoc duration

Time management

Learn to manage people in small groups can be less likely to happen

Lack of time to learn skills; fractured time can be hard to use

Time and resources

Cultural background

"Labeling" people e.g. "mentor"

Location of the institute

Institute is promoting too much independence

Units can be isolated

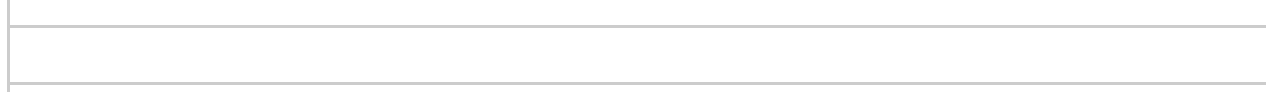

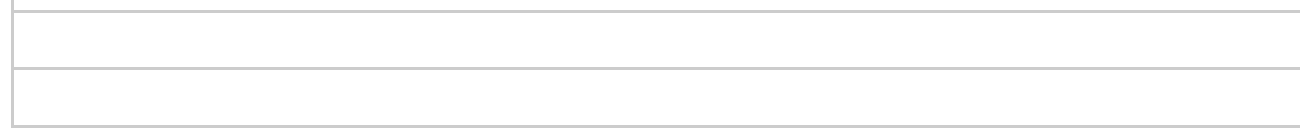

\section{Okinawa Institute of Science and Technology: $n=10$}

\section{Solutions}

Need to finish current projects that were not your own

PI/Supervisor Dictates Project

Communicating with Community

Lack of trainings (management, financial)

Lack of opportunities to showcase own abilities of leadership role for grad students

Where the line for independence is? e.g. in terms of use of research funding

Input from PI - how much? - phase out over time?

Interests of $\mathrm{PI}$ coinciding

Getting feedback

More communication with PI; convincing PI for interests

Increase transparency in funding processes

Get own grants/convince university/panels for grants -> independence to self-budget

Proactively seek out other opportunities - volunteering - mentoring -> time

management

Communication with peers

Team building (collaborators)

What career do I want (5yr - 10yr)

Seeing your big picture vs someone else's

Write your own grant...while managing your current project

Knowing the system 


\section{Solutions}

Priority list; keep track of what the PI is asking and show [them] results of own research

Deal with it; communicate with others about systems and structures

Make it clear that [you] may take the projet away with you; change the way research is done so to ensure longer postdocs

Opportunity to mentor or teach

Opportunity to apply [for a] grant

Identification of particular skills within institution - database with skills i.e.

"labeling" 
Supplementary Table S5D. Raw data of all barriers faced, and solutions proposed, by ECRs during workshops at the University of California Irvine (2018).

\section{University of California Irvine: $n=43$}

\section{Barriers}

\section{Group 1}

Lack of enough money

Gaps of knowledge

International researchers have limited available of grants they can write

Lack of communication between faculty and trainees

Taking care of oneself under high expectation environment

Being worked as a tech without guidance or intellectual stimulation

Not being allowed to take project with me (sabotage)

Lack of enough transition grants for postdocs

Pls do not encourage "alternate" careers

PI (branding) reputation monopoly on position for "their" postdocs

Delaying publications to secure grants

Unethical hiring \& firing practices, high turnover, where is HR?

Time + initial correspondence to apply for transition grants

Evil PI coercion (Do this or get fired!)

Putting multiple lab members on same project and then taking data away from all but only

1 for publication

Unethical incentives - Not working on own paper

CV profiling (age, university, subject of research)

Maternity leave paternity leave (childcare)

\section{University of California Irvine: $n=43$}

\section{Solutions}

\section{Group 1}

Find good PI

Project/maintain identify

Keep options open so your skill set is broad

Find $\mathrm{Pl} /$ mentor who has best interests in mind e.g allows intellectual development

Remember why you love science!

Being informed about what careers there are for PhDs, besides academic

Pathway: Attend more GPS-BIOMED talks to stay informed

More protection for postdocs. Commensurate salary based on cost of living

Support network - friends, family, professional 


\section{Group 2}

Credibility

Lack of strong network

Academic politics

Lack of responsiveness from $\mathrm{PI}$

Lack of communication with PI

\section{Group 3}

Funding: internal money dictates research; lack of resources

Time scale of research

\section{Lack of independence}

\section{Small paychecks}

personal considerations (Spousea0

Bias against science in community

Bias against immigrant researchers

Teaching vs research institutes

Duties and problems

Grants open to native researchers and less for international scholars

Pigeon holes into roles

Research tunnel vision

Limited funding sources to draw from

Issues as minority in science - women, URM

Lack of training for non-research responsibilities

Lack of training on time management

Lineage in science - If PI is great, then only you can land up in a good postdoc or faculty position

Limited resources - instruments

\section{Group 2}

Projecting confidence

Figuring out what you don't know so you can learn it

Improve management skills

\section{Group 3}

PI with better management skills

Transparency about expectation in research

Less narcissism

Less judgement about work/life balance

Treat not like a tech 


\section{Barriers}

\section{Group 4}

Imposter syndrome

Lack Funding to do your own research

Lack of confidence

No differentiation between postdocs \& graduate students. Same work, same life

Lack of training to identify good research paths to follow

Lack of creativity to find new research directions

Lack of work-life balance

Tracking research which is not your speciality

\section{Group 5}

Bad training/mentoring

Too much workload

Unrealistic expectations

Hands-off approach/no training

No help with project or intellectual freedom

Not helpful with all the managerial and regulatory tasks

Close minded to career exploration

$\mathrm{PI}$ not ready to involve you in grant writing or project planning

Lack of willingness to collaborate and interact with other researchers and groups

\section{Solutions}

\section{Group 4}

Treat imposter syndrome

Anonymity while complaining

Form a mentoring team

Preparation for faculty job applications

Support groups

Join professional organizations

Communication skills training

Networking

\section{Group 5}

Prioritize workload

Set short term goals

Utilize available resources (core facilities, collaborators)

Open talk with the PI

Training reach-out to other mentors

Don't be afraid to try to change the lab culture

Find alternative sources of mentoring

Ignore your problems 


\section{Barriers}

Solutions

Group 6

\section{Group 6}

The group left due to time constraints. However, the team discussed their solutions in a team. To keep the consistency in quotes from

Comparison with groups who publish high impact \& get all the opportunities participants, we decided to not add any of the quotes we heard

Collaboration balance with Independence

Luck in research project

Sacrifice a lot to become an independent researcher, values, relationships, time, holidays

\section{Money}

Gaps of knowledge

Imposter Syndrome

Lack of role models

No high impact paper

no money for tech or lab manager \& therefore end up doing extra jobs on top of $\mathrm{grad} /$ postdoc research

Too many undergrads to supervise, no training to read $\&$ write

People willing to proof (?)

Networking for grant money 
Supplementary Information 1. Stakeholder-specific detailed solutions proposed by ECRs to achieve independence from both U.S. and Japan workshops.

\section{ECRs}

- Keep track of Pls expectations - making a list of Pls expectations and organizing them into the order of priority will help to not only say 'No' to things which shouldn't be expected but will also help to achieve research goals and have time left for career development activities. Keeping regular contact with PI about progress will help focus.

- Take charge of your career - ECRs should proactively engage in career building and look for avenues and resources for it. Attend career and professional development events, on-campus \& off-campus

- Peer networks - Share with peers and form support groups to get help with career progress.

- Apply for grants/fellowships - Pls should encourage their graduate students and postdocs to apply for grants in pursuing their own research ideas and gain independence from Pl's grants.

- Identify good mentors - Find a good mentor who encourages independence

- $\quad$ Immigration rules landscape - stay aware of changing landscape of immigration rules \& keep in touch with your institute's international office

- $\quad \mathrm{NIH}$ Salary - keep track of NIH salary scales and if institutions follow the NIH salaries for postdocs

- Maintain work-life balance - Lay out clear working hours and time off \& seek mental health resources available to students and postdocs on campus

\section{PIs, Departments \& Research Institutes}

- Mentors should be mentored - Pls should undergo training on how to train young researchers.

- Eocused mentoring - Pls should focus on training their students and postdocs instead of expecting them to learn by themselves.

- Collaborative science - Pls should be more involved in starting collaborations with other researchers in the field and allowing ECRs to be part of it.

- Education for other career paths - Pls should be made aware about other career paths emanating out of the PhD training in order to help ECRs find their future job.

- Independence in writing grants - Trainees should be allowed to write their own grants and fellowships

- Career development opportunities - ECRs should be provided with resources and training for career development, both academic or non-academic.

- Comprehensive evaluation of PIs - Institutions should evaluate Pls for tenureship based on their track record of training ECRs to be independent researchers, mentoring, career guidance and those who allow freedom of thinking in science. Additionally, ECRs should be made part of the decision-making process.

- Uniform guidelines - the training for ECRs should be formalized and made uniform. Structured training with well defined responsibilities and expectations will prevent exploitation of graduate students and postdocs by their respective Pls.

- Eormalized curriculum - training for other science or non-science careers should be made part of the curriculum. Courses in science communication, the business of science, industry research or event time for industry internships should be included in the curriculum.

- Graduate and postdoctoral affairs offices - should provide career resources, alumni lists and other job portals to prepare ECRs for the job market.

- Encourage hiring young faculty - seasoned researchers who can not get grants anymore should be asked to retire to make the jobs available for young faculty with fresh research ideas.

- Uniform payscale and benefits - a uniform NIH pay scale and benefits should be followed to reward postdocs for their time and efforts. Additionally, tenureship decisions should be made on how well their Pls take care of their ECRs by providing them with competitive salary and benefits.

- Postdoc levels - different levels for postdocs should be included, early, mid-level and senior levels to allow for appropriate training and a smooth transition to faculty roles. Adding tenure researcher levels for postdocs will ensure independence and job security.

- Career development opportunities - Research institutes and universities should add career development opportunities in training ECRs.

\section{Funding agencies}

- $\quad$ Incentives for independence - rewards for independence and independent research projects should be provided by granting agencies. Implement motivational grants to help pursue novel ideas.

- Mandatory career training- granting agencies should ensure that specific plans for career development of ECRs are made part of the grant.

- Remove restrictions on grant eligibility - international researchers should be made eligible for all granting agencies. The number of years as postdoc eligibility should be relaxed. Postdocs training period has increased over the years, yet eligibility to apply for postdoc grants has remained the same.

- Collaborative grants - collaborative projects and grant ideas should be encouraged to allow communication between different groups conducting research on similar topics.

- Mobility of postdoc grants - postdocs should be allowed to take their grants with them, if they decide to change labs/institutions based on special circumstances.

- Iransparency in the funding process - The current funding process has an implicit bias towards seasonal PIs and PIs tend to favor grants from researchers known to them. A more transparent funding mechanism needs to evolve, so young Pls face fair competition.

- Money for career and professional development programming - Funding agencies should earmark money for career \& professional development programs in awarded grants 


\section{Legend (NASEM report)}

- Graduate STEM Education for the 21st Century (2018)

- The Next Generation of Biomedical and Behavioral Sciences Researchers: Breaking Through (2018)

- Sexual Harassment of Women: Climate, Culture, and Consequences in Academic Sciences, Engineering, and Medicine (2018)

- The Science of Effective Mentorship in STEMM (2019)

- Bridges to Independence: Fostering the Independence of New Investigators in Biomedical Research (2005)

Note: this is not a comprehensive list of all the recommendations from the reports. 
5.1 Core competencies for Ph.D. education:

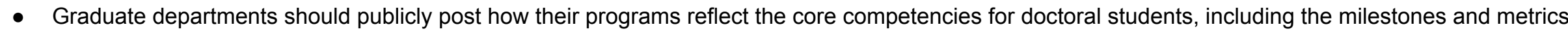
the departments and individual faculty use in evaluation and assessment.

5.2 Career exploration and preparation for Ph.D. students:

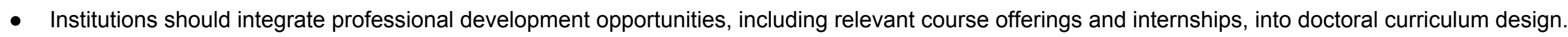

- Industry, nonprofit, government, and other employers should provide guidance and financial support for relevant course offerings at institutions and provide internships and other forms of professional experiences to students and recent graduates.

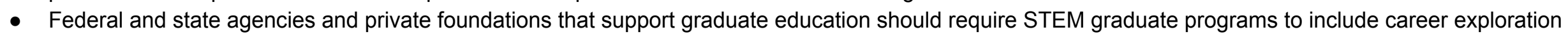

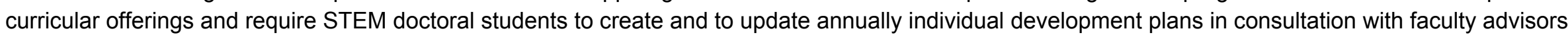
to map educational goals, career exploration, and professional development.

National Institutes of Health:

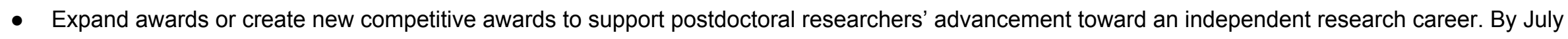
2023, there should be a 5-fold increase in the number of individual research fellowship awards (F-type) and career development (K-type) awards for postdoctoral researchers granted. This goal should be achieved incrementally and steadily during this period. The indirect recovery cost rate earned by K-type and training awards should be increased to 16 percent.

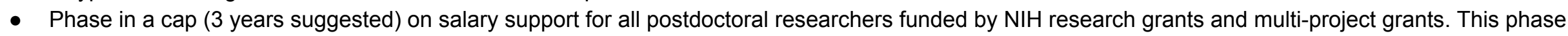

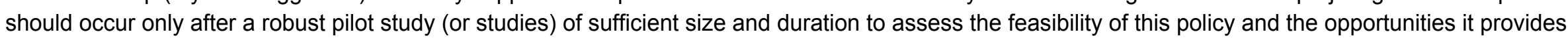
has been undertaken.

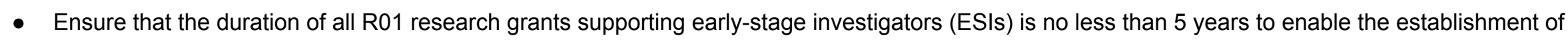
resilient and independent research programs. NIH Institutes and Centers should experiment with further extending the duration of R01 awards for ESIs.

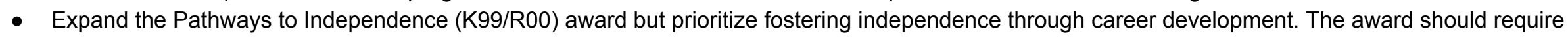
development of an innovative and independent research project that is conceived of and executed by the applicant. The award should not represent additional or new training.

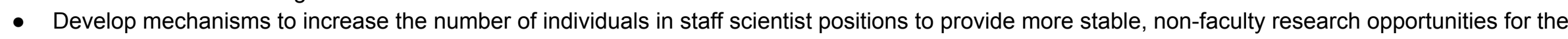
next generation of researchers.

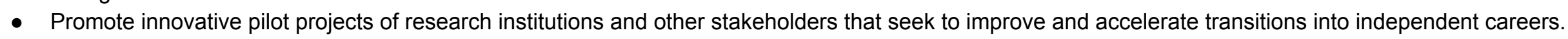
Create a Next Generation Researcher Innovation Fund to support these experimental projects.

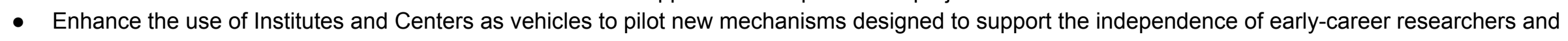
thereby strengthen $\mathrm{NIH}$ capacity for innovation more broadly. Monitor and evaluate these pilots through the Biomedical Research Enterprise Council proposed above.

Biomedical research institutions:

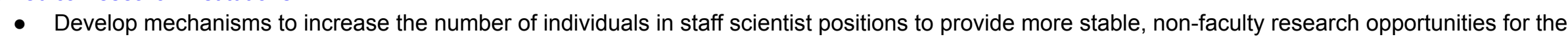
next generation of researchers.

- Provide individuals in the staff scientist track with salaries and benefits commensurate with their experiences and responsibilities.

Principal investigators: 
- Provide every postdoctoral researcher with a high-quality training experience that prepares them for a successful research career.

- Provide a postdoctoral training and mentoring plan in all grant proposals and updates of those plans in all progress reports to NIH if funded.

5 Support multiple mentorship structures:

- 5.2 Mentors should provide opportunities and support for mentees in mentoring relationships with other individuals within and outside of their home department, program, or institution (such as professional societies, external conferences, learning communities, online networks) who can provide complementary or supplementary functions that enable mentees to progress and succeed.

- 5.4 Professional associations should proactively facilitate the development of mentoring relationships among individuals from different programs or institutions, as needed, who can provide complementary or supplementary mentorship functions. This could include activities such as pairing first-time conference attendees (mentees) with returning conference attendees (mentors) to orient them to conference events and support their networking or establishing and supporting online communities for mentees to find and make supportive connections outside their own institutions and environments (e.g., academia).

4.1 Length of postdoctoral appointment:

- NIH should enforce a 5-year limit on the use of any funding mechanism-including research grants-to support postdoctoral researchers. The nature of the position, including responsibilities and benefits, should change for those researchers who transition to staff scientist positions after 5 years.

4.2 Reallocate NIH resources for postdoctoral support:

- Postdoctoral researchers should be more independent and less dependent on the research grants of PIs. NIH should reallocate some of the resources for postdoctoral support away from the R01 and toward individual awards and training grants.

4.4 Independent funding:

- A new research award is needed at NIH to provide postdoctoral researchers with the opportunity to conduct an independent project under the mentorship of a senior investigator. This postdoctoral independent research award would complement, but not replace, the existing NRSA.

5.1 Career transition research grants:

- $\mathrm{NIH}$ should establish a program to promote the conduct of innovative research by scientists transitioning into their first independent positions. These research grants, to replace the collection of K22 awards, would provide sufficient funding and resources for promising scientists to initiate an independent research program and allow for increased risk-taking during the final phase of their mentored postdoctoral training and during the initial phase of their independent research effort. The program should make 200 grants annually of $\$ 500,000$ each, payable over 5 years. 
3.3 Comprehensive national and institutional data on students and graduates:

- Institutions should develop a uniform, scalable, and sustainable model for data collection that can operate beyond the period of extramural funding. The data collection should follow standard definitions that correspond with national STEM education and workforce surveys to help inform benchmarking or higher education research.

- Prospective students should use these data to inform graduate program selection, educational goal development, and career exploration.

National Science Foundation:

- Develop and implement a plan to improve sector-wide data collection and analysis in a manner that is easily accessible by policymakers and that integrates data from numerous other sources.

- Work expeditiously to link the Survey of Doctorate Recipients and the Survey of Earned Doctorates to U.S. Census data, and then make those linked data, under strict confidentiality protocols, available to qualified researchers at Federal Statistical Research Data Centers to understand better the biomedical workforce.

National Institutes of Health:

- Phase-in policies that require the collection and publication of data on outcomes and demographics of biomedical pre- and postdoctoral researchers, using common standards and definitions, as a prerequisite for further funding to incentivize compliance.

- Continue to improve the peer-review process to optimize the evaluation of applications submitted by early-stage and early experienced investigators in the Next Generation Researchers Initiative. This is of special importance for investigators from underrepresented groups.

Biomedical research institutions:

- Collect, analyze, and disseminate comprehensive data on outcomes, demographics, and career aspirations of biomedical pre- and postdoctoral researchers using common standards and definitions as developed in concert with $\mathrm{NIH}$.

- Experiment with creating career tracks for staff scientists with clearly defined review and promotion processes, as well as opportunities for professional development.

4.6 Broaden educational opportunities:

- Postdoctoral scientists should receive improved career advising, mentoring, and skills training. Universities, academic departments, and research institutions should broaden educational and training opportunities for postdoctoral researchers to include, for example, training in laboratory and project management, grant writing, and mentoring. NIH should take steps to foster these changes, including by making funds available to facilitate these endeavors.

4.7 Need for better data and program evaluation:

- NIH should develop enhanced data collection systems on postdoctoral researchers to include all NIH-supported postdoctoral researchers, regardless of specific funding mechanism. This will allow NIH to track the effectiveness of its programs and thereby make more informed programmatic decisions.

5.2 Program assessment:

- NIH should develop enhanced data collection systems on staff scientists and other non-tenure-track researchers to include all NIH supported researchers, regardless of specific funding mechanism. This will allow $\mathrm{NIH}$ to track the effectiveness of its programs and thereby make more informed programmatic decisions.

6.4 Data collection: 
- $\mathrm{NIH}$ should develop enhanced data collection systems on all NIH-supported researchers, regardless of specific funding mechanism. This will allow NIH to track the effectiveness of its programs, make more informed programmatic decisions, and monitor the career progression of supported researchers. 
3.1 Rewarding effective teaching and mentoring:

- Institutions should increase priority and reward faculty for demonstrating high-quality teaching and inclusive mentoring practices for all graduate students, including the recognition of faculty teaching in master's degree programs, based on the results of restructured evaluations.

- Institutions should include teaching and mentoring performance as important considerations for reappointment, promotion, annual performance review, and tenure decisions. Institutions should also nominate faculty for external awards (such as those from technical societies) that reward teaching excellence.

3.2 Institutional support for teaching and mentoring:

- Institutions should require faculty and postdoctoral researchers who have extensive contact with graduate students to learn and demonstrate evidence-based and inclusive teaching and mentoring practices.

- Graduate students should seek multiple mentors to meet their varied academic and career needs.

National Institutes of Health:

- Require the inclusion of an institutional training and mentoring plan as a component of the "Resources and Environment" section of grant applications.

- Require principal investigators (PIs) to provide a postdoctoral training and mentoring plan in all grant proposals that will support postdoctoral researchers and to update those plans in progress reports.

Biomedical research institutions:

- Provide evidence to NIH of formal training of faculty mentors of postdoctoral trainees.

- Levy a fee of at least $\$ 1,000$ per year for each postdoctoral fellow supported on all biomedical research grants. These fees should be used to support effective training and professional development programs for postdoctoral researchers, as well as effective training of mentors. The use of the fees should be reported publicly.

Principal investigators:

- Receive formal training from their research institutions on mentoring postdoctoral trainees.

- Provide a postdoctoral training and mentoring plan in all grant proposals and updates of those plans in all progress reports to NIH if funded.

3 Establish and use structured feedback systems:

- 3.3 Mentors and mentees should work with each other and their institutions to develop feedback systems to document, evaluate, and advance mentorship competencies over time using established methods and instruments for measuring mentorship effectiveness. They should also participate in institutional reviews of formal mentorship activities and programs to enhance mentor and mentee outcomes and inform periodic self-reflection.

8 Recommendations for funding agencies that support mentorship:

- 8.1 Funding agencies should encourage the integration of evidence-based mentorship education for mentors and mentees and assessments of mentorship into grant activities that involve undergraduate and graduate student research, education, and professional development to support the development of the next generation of talent in STEMM.

- 8.2 Funding agencies, when supporting STEMM student development, should require tools such as mentoring compacts and individual development plans to operationalize intentionality and promote shared understanding of the goals of mentoring relationships on sponsored projects.

4.5 Clarifying the mentorship responsibilities of PIs: 
- NIH should modify the application for R01s so that requests for postdoctoral research positions include a description of how the postdoc will be prepared for an independent career (training) and a description of the elements of the proposed project in which the postdoctoral researcher will be involved. Pls should provide basic information for all current postdocs and those supported within the last 10 years to include name, time in the laboratory, and their current title and institution. 
Barriers faced by international scholars

3.4 Funding for research on graduate STEM education:

- Funders should support research on the effect of different funding mechanisms on outcomes for doctoral students, including traineeships, fellowships, teaching and research assistantships; the effects of policies and procedures on degree completion, disaggregated by gender, race and ethnicity, and citizenship; and the effect of expanding eligibility of international students to be supported on federal fellowships and training grants.

National Institutes of Health:

- The National Institutes of Health (NIH) should expand existing awards or create new competitive awards to support postdoctoral researchers' advancement of their own independent research and to support professional development toward an independent research career. Both domestic and foreign postdoctoral researchers should be eligible for these awards.

4.3 Reallocate NIH resources for postdoctoral support:

- In order to provide equal opportunities for non-U.S. citizens, the citizenship requirement for NRSAs and related postdoctoral training awards should either be modified, or alternative and equivalent mechanisms of support should be available for those who are not U.S. citizens or permanent residents. 


\subsection{Funding for research on graduate STEM education:}

- Funders should support research on the effect of different funding mechanisms on outcomes for doctoral students, including traineeships, fellowships, teaching and research assistantships; the effects of policies and procedures on degree completion, disaggregated by gender, race and ethnicity, and citizenship; and the effect of expanding eligibility of international students to be supported on federal fellowships and training grants.

National Institutes of Health:

- Increase the Ruth L. Kirschstein National Research Service Award (NRSA) starting salary for new postdoctoral researchers to $\$ 52,700$ (in 2018 dollars), with annual increases for inflation and for cost-of-living tied to the Personal Consumption Expenditure Index.

- Research institutions should levy a fee of at least $\$ 1,000$ per year, to be paid by the host investigator, for each postdoctoral fellow on all biomedical research grants. Funds from the fee would be used to support effective training and professional development programs for postdoctoral researchers, as well as effective training of mentors. Research institutions should report publicly on the use of the money generated by this fee.

Biomedical research institutions:

- Adjust the base postdoctoral salary annually to match the corresponding NRSA rate, with increases based on local cost-of-living, and harmonize benefits for all postdoctoral scholars regardless of their support mechanism.

- Limit postdoctoral training to 5 years, after which postdoctoral researchers continuing in the same laboratory should be shifted to employment as a staff scientist with an increase in salary and benefits appropriate for a permanent staff member.

6.3 Providing for enhanced job security:

- Non-tenure-track "soft-money" researchers should have a budgetary "safety net" that provides time to reapply for grant support if their funding lapses. This safety net should be a joint responsibility of the $\mathrm{NIH}$ and the host institution: $\mathrm{NIH}$ should expand the Shannon Award to provide merit-based bridge awards for those without other sources of support and host institutions should offer multi-year renewable contracts to its staff scientists that guarantee space, salary, and minimal research support even in the absence of external funding. 
Misalignment with academic system and culture

3.7 Stronger support for graduate student mental health services:

- Institutions should administer periodic climate surveys of graduate students at the departmental level to assess their well-being in the aggregate and make adjustments when problems are identified.

- Institutions should take extra steps to provide and advertise accessible mental health services, such as those already available to veterans and most undergraduate students, at no cost to graduate students.

- Graduate programs should allow students to have an active and collaborative voice to proactively engage in practices that support holistic research training and diverse career outcomes and that allow students to provide feedback on their experiences.

Biomedical research institutions:

- Identify or provide an institutional ombudsperson to resolve fairly and expeditiously conflicts and concerns between principal investigators and postdoctoral researchers related to the training experience. 
Additional broader recommendations

3.6 A dynamic graduate STEM education system:

- Faculty and graduate departments and programs should periodically review and modify curricula, dissertation requirements, and capstone projects to ensure timeliness and alignment with the ways relevant work is conducted and provide students with opportunities to work in teams that promote multidisciplinary learning.

5.3 Structure of doctoral research activities:

- Students should seek opportunities to work in cross-disciplinary and cross-sector teams during their graduate education and via extracurricular activities and be incentivized by their departments and faculty advisors to do so. 
3.5 Ensuring diverse, equitable, and inclusive environments:

- Institutions, national laboratories, professional societies, and research organizations should develop comprehensive strategies that use evidence-based models and programs and include measures to evaluate outcomes to ensure a diverse, equitable, and inclusive environment.

- Institutions should develop comprehensive strategies for recruiting and retaining faculty and mentors from demographic groups historically underrepresented in academia.

National Institutes of Health:

- Continue to improve the peer-review process to optimize the evaluation of applications submitted by early-stage and early experienced investigators in the Next Generation Researchers Initiative. This is of special importance for investigators from underrepresented groups.

- Revise the biosketch requirement to focus peer review on recent contributions and accomplishments and continue to test effective practices for reducing the effects of implicit bias and for increasing the diversity of reviewers.

Biomedical research institutions:

- Promote, document, and disseminate existing and planned efforts, both independent and collaborative, to reduce the barriers to recruiting and retaining diverse researchers for pre- and postdoctoral positions and the initial stages of research independence.

Principal investigators:

- Provide a diversity and inclusion plan in all grant proposals and updates of those plans in all progress reports to NIH if funded.

1 Create diverse, inclusive, and respectful environments:

- Academic institutions and their leaders should take explicit steps to achieve greater gender and racial equity in hiring and promotions, and thus improve the representation of women at every level.

- Academic institutions and their leaders should take steps to foster greater cooperation, respectful work behavior, and professionalism at the faculty, staff, and student/trainee levels, and should evaluate faculty and staff on these criteria in hiring and promotion.

3 Move beyond legal compliance to address culture and climate:

- Academic institutions, research and training sites, and federal agencies should move beyond interventions or policies that represent basic legal compliance and that rely solely on formal reports made by targets. Sexual harassment needs to be addressed as a significant culture and climate issue that requires institutional leaders to engage with and listen to students and other campus community members.

4 Improve transparency and accountability:

- Academic institutions should be as transparent as possible about how they are handling reports of sexual harassment. This requires balancing issues of confidentiality with issues of transparency. Annual reports, that provide information on (1) how many and what type of policy violations have been reported (both informally and formally), (2) how many reports are currently under investigation, and (3) how many have been adjudicated, along with general descriptions of any disciplinary actions taken, should be shared with the entire academic community: students, trainees, faculty, administrators, staff, alumni, and funders. At the very least, the results of the investigation and any disciplinary action should be shared with the target(s) and/or the person(s) who reported the behavior.

5 Diffuse the hierarchical and dependent relationship between trainees and faculty:

- Academic institutions should consider power-diffusion mechanisms (i.e., mentoring networks or committee-based advising and departmental funding rather than funding only from a principal investigator) to reduce the risk of sexual harassment.

7 Strive for strong and diverse leadership: 
- Leadership training programs for those in academia should include training on how to recognize and handle sexual harassment issues, and how to take explicit steps to create a culture and climate to reduce and prevent sexual harassment-and not just protect the institution against liability.

13 Increase federal agency action and collaboration:

- Require institutions to report to federal agencies when individuals on grants have been found to have violated sexual harassment policies or have been put on administrative leave related to sexual harassment, as the National Science Foundation has proposed doing. Agencies should also hold accountable the perpetrator and the institution by using a range of disciplinary actions that limit the negative effects on other grant personnel who were either the target of the harassing behavior or innocent bystanders.

15 Make the entire academic community responsible for reducing and preventing sexual harassment:

- All members of our nation's college campuses—students, trainees, faculty, staff, and administrators—as well as members of research and training sites should assume responsibility for promoting civil and respectful education, training, and work environments, and stepping up and confronting those whose behaviors and actions create sexually harassing environments.

4 Recognize and respond to identities in mentorship:

- 4.1 Institutional leadership should intentionally support mentorship initiatives that recognize, respond to, value, and build upon the power of diversity. Leaders should intentionally create cultures of inclusive excellence to improve the quality and relevance of the STEMM enterprise. 


\section{Congress:}

- Establish a Biomedical Research Enterprise Council (BREC) to address ongoing challenges confronting the Next Generation of Biomedical Researchers. The BREC would exercise ongoing collective guardianship of the biomedical enterprise function as a forum for sustained coordination, consultation, problem-solving, and assessment of progress toward implementation of the recommendations put forth in this report.

- Consider increasing the NIH budget, specifically to implement the recommendations in this report and to sustain NIH's recently announced Next Generation Researchers Initiative.

- Promote innovative pilot projects on the part of research institutions and other stakeholders that seek to improve and accelerate transitions into independent careers. A Next Generation Researcher Innovation Fund should be created to support these experimental projects.

11 Initiate legislative action:

- Prohibiting confidentiality in settlement agreements that currently enable harassers to move to another institution and conceal past adjudications.

- Requiring institutions receiving federal funds to publicly disclose results from campus climate surveys and/or the number of sexual harassment reports made to campuses. 